Illinois State University

ISU ReD: Research and eData

Theses and Dissertations

6-25-2019

\title{
A Critical Walk Down Illinois Career Pathways
}

Michael Cermak

Illinois State University, michaelcermak@comcast.bet

Follow this and additional works at: https://ir.library.illinoisstate.edu/etd

Part of the Higher Education Administration Commons

\section{Recommended Citation}

Cermak, Michael, "A Critical Walk Down Illinois Career Pathways" (2019). Theses and Dissertations. 1188. https://ir.library.illinoisstate.edu/etd/1188

This Dissertation is brought to you for free and open access by ISU ReD: Research and eData. It has been accepted for inclusion in Theses and Dissertations by an authorized administrator of ISU ReD: Research and eData. For more information, please contact ISUReD@ilstu.edu. 


\section{A CRITICAL WALK DOWN ILLINOIS CAREER PATHWAYS}

\section{MICHAEL CERMAK}

\section{Pages}

This study analyzes high school Career and Technical Education (CTE) course enrollments in Illinois public high schools. Emphasis is placed on considering how enrollments of students of color differs from their white peers. Gender and racial imbalances prove pronounced in STEM-related career pathways and reveal a large proportion of students of color enrolled in courses leading to low-skill, service-sector occupations. Given future economic and social implications, I recommend future researchers consider how students of color select and how underrepresented students are placed by institutional members and practices into CTE courses.

KEYWORDS: career and technical education, career pathways, CTE, STEM, equity, whiteness studies 


\section{A CRITICAL WALK DOWN ILLINOIS CAREER PATHWAYS}

\section{MICHAEL CERMAK}

A Dissertation Submitted in Partial

Fulfillment of the Requirements

for the Degree of

DOCTOR OF PHILOSOPHY

Department of Educational Administration and Foundations

ILLINOIS STATE UNIVERSITY 
(C) 2020 Michael Cermak 


\title{
A CRITICAL WALK DOWN ILLINOIS CAREER PATHWAYS
}

\author{
MICHAEL CERMAK
}

COMMITTEE MEMBERS:

Stacy Otto, Chair

Lydia Kyei-Blankson

Chris Merrill

James Palmer 


\section{ACKNOWLEDGMENTS}

Gratitude and thanks go to Dr. Chris Merrill, a dear friend and colleague, who is responsible for my whole $\mathrm{PhD}$ endeavor when he said, "You're asking research questions. You need to go back to school!” My committee: Drs. Kyei-Blankson, Lin, Merrill, Otto, and Palmer who make me think and read differently, it really was and still is a transforming experience.

Super-big thanks to Dr. Stacy Otto for all the meetings at the "usual place" and the overall good dissertation juju, whew. Especially, for Jo and her enormous patience throughout the process who, at the beginning of this endeavor, stated politely, "Just finish."

M.C. 


\section{CONTENTS}

Page

ACKNOWLEDGMENTS

TABLES - vi

CHAPTER I: HOW CTE “KEEPS AMERICA COMPETITIVE” 1

$\begin{array}{ll}\text { Introduction } & 1\end{array}$

$\begin{array}{ll}\text { Career Pathways and Pipelines } & 4\end{array}$

$\begin{array}{ll}\text { Statement of the Problem } & 8\end{array}$

Pairing Descriptive Statistical Analysis with Interpretivist Critical Re-Analysis $\quad 9$

$\begin{array}{ll}\text { Impetus for the Study } & 10\end{array}$

$\begin{array}{ll}\text { Situating in the Literature } & 12\end{array}$

$\begin{array}{ll}\text { Research Questions } & 14\end{array}$

CHAPTER II: REVIEW OF THE LITERATURE 15

$\begin{array}{ll}\text { Introduction } & 15\end{array}$

$\begin{array}{ll}\text { History of CTE } & 16\end{array}$

$\begin{array}{ll}\text { Vocationalism } & 17\end{array}$

National Society for the Promotion of Industrial Education $\quad 18$

Smith-Hughes ACT of $1917 \quad 19$

DuBois and Washington Debate Manual Training 21

The Vocational Education Act of 1963 and Title IX 22

$\begin{array}{ll}\text { Perkins Act } & 23\end{array}$

Program of Study (PoS), Career Pathways, and Career Clusters 24 
$\begin{array}{ll}\text { Alignment } & 26\end{array}$

$\begin{array}{ll}\text { Credentials } & 27\end{array}$

$\begin{array}{ll}\text { STEM Career Pathways } & 29\end{array}$

$\begin{array}{ll}\text { Race in CTE Literature } & 30\end{array}$

$\begin{array}{ll}\text { Conclusion } & 31\end{array}$

CHAPTER III: METHODOLOGY

$\begin{array}{ll}\text { Research Design } & 33\end{array}$

Data-Set General Characteristics $\quad 34$

Levels of Analyses $\quad 36$

$\begin{array}{ll}\text { Univariate Analysis } & 37\end{array}$

$\begin{array}{ll}\text { Bivariate Analysis } & 38\end{array}$

Multivariable Analysis/Logistic Regression $\quad 39$

$\begin{array}{ll}\text { Limitations } & 39\end{array}$

$\begin{array}{ll}\text { Theoretical Frame } & 41\end{array}$

$\begin{array}{ll}\text { Critical Whiteness Studies } & 42\end{array}$

Whiteness as Property $\quad 45$

$\begin{array}{ll}\text { Meritocracy } & 46\end{array}$

$\begin{array}{ll}\text { Colorblindness } & 48\end{array}$

$\begin{array}{ll}\text { Individualism } & 49\end{array}$

CHAPTER IV: DATA ANALYSIS $\quad 50$

$\begin{array}{ll}\text { Introduction } & 50\end{array}$

$\begin{array}{ll}\text { Descriptive Statistical Analysis } & 50\end{array}$

State Demographics $\quad 51$ 
Demographics by Race $\quad 51$

Illinois CTE Public High School Enrollment Demographics 52

Demographics by Gender $\quad 53$

Student Location Demographics $\quad 54$

Enrollment Patterns of Students of Color Compared to White Students 57

Analysis Using Logistic Regression $\quad 62$

Asian Students More Likely to Be Enrolled in STEM Courses 65

CTE Enrollments with Parity $\quad 66$

Majority of CTE Courses Are Introductory in Scope 66

$\begin{array}{ll}\text { Reanalysis of the Descriptive Analysis } & 67\end{array}$

Enrollment Differences Between STEM-Related and Family \& Consumer Science

$\begin{array}{ll}\text { Courses } & 67\end{array}$

Majority of Students of Color Enrolled in Service-Sector Pathways 70

Agricultural Enrollments Show Exclusion of Most Students of Color $\quad 72$

CHAPTER V: FINDINGS, IMPLICATIONS, AND RECOMMENDATIONS 76

$\begin{array}{ll}\text { CTE as a Tracking Mechanism } & 76\end{array}$

$\begin{array}{ll}\text { A Pipeline Devoid of Color } & 77\end{array}$

Focusing on Systemic Inequities Rather than STEM 78

Service-Sector Jobs for Students of Color $\quad 79$

$\begin{array}{ll}\text { Limitations } & 79\end{array}$

$\begin{array}{lr}\text { Data Collection } & 80\end{array}$

Recommendations for Practice $\quad 81$

$\begin{array}{lr}\text { Credentials } & 82\end{array}$ 
Reward CTE Systems That Promote Sampling

Recruit Instructors of Color

REFERENCES

85

APPENDIX A: VARIABLE DESCRIPTIONS

98

APPENDIX B: PLAN OF STUDY

101 
Table

\section{TABLES}

1. 2015-2016 Illinois Total Public School Enrollment by Race 51

2. 2015-2016 Total Illinois Public High School CTE Enrollment by Race 53

3. 2015-2016 Total Illinois Public High School Enrollment by Gender 54

4. 2015-2016 Total Illinois Public High School CTE Enrollment by Gender 54

5. 2015-2016 Chicago Public School CTE Enrollment 55

6. 2015-2016 Top Three Chicago Public School CTE Courses with Most Enrollment 55

7. 2015-2016 Top Three Chicago Public School CTE Enrollment as Percentages by Race 56

8. 2015-2016 EFE 150 CTE Enrollment 57

9. 2015-2016 Top Half Illinois Public High School CTE Enrollment 58

10. 2015-2016 Top 13 CTE Enrolled Classes with Race and Percent Race by Course 59

11. Binary Logistic Regression: STEM and Gender 64

12. Logistic Regression for STEM CTE Enrollment 64

13. 2015-2016 Illinois Public High School Health Occupations Enrollment by Race and

$\begin{array}{ll}\text { Percent of Course } & 66\end{array}$

14. 2015-2016 Illinois Public High School STEM Enrollment by Race and Percent of Course 68

15. 2015-2016 Illinois Public High School Nutrition and Culinary Arts I \& II Enrollment by

$\begin{array}{ll}\text { Race and Percent of Course } & 70\end{array}$

16. 2015-2016 Illinois Public High School Agricultural Enrollment by Race and Percent of

Course 


\section{CHAPTER I: HOW CTE “KEEPS AMERICA COMPETITIVE” Introduction}

Career and technical education (CTE) is a robust curricular area within Illinois public schools. Illinois State Board of Education (2017) data show over a quarter of a million students in Illinois' public high schools enroll in at least one CTE class each school year. A main tenet of CTE, and one with historical roots dating back to the Morrill Act of 1862 (U.S. Congress, 1862), places emphasis on technical training linked to industry to keep the U.S. industrial juggernaut humming. As the industrial revolution modernized plants and processes, many more workers with technical knowledge were needed. In the 1860s, technical training focused on agriculture and was intended to provide students with practical skills that could be used in and around their farms' fields (Gordon, 2008). Today, CTE encompasses many digital technologies, but nevertheless is still viewed as a practical, hands-on form of education designed to assist workers in adapting to the changing workforce. Organizations and trade groups often lament how fast their respective industries change and issue urgent calls for more- and better-qualified workers; those groups depend upon CTE to provide workers with practical knowledge to retain the U.S.' competitive industrial and technological edge.

For instance, a recent report from the U.S. Department of Health and Human Services (HHS) (2017) offers information on the future healthcare workforce's readiness and the risks faced nationally if more is not done to increase the number of healthcare workers since, "by 2025, demand is expected to exceed supply for several critical health professions" (p. 25). If predicted shortages persist, the literal health and well-being of the U.S. will be in jeopardy. HHS report authors stress the importance and utility of maintaining viable CTE programs in high 
schools and community colleges as one way to ensure a critical shortage of healthcare workers can be addressed and overcome.

Similarly, manufacturing groups like the National Association of Manufacturers (NAM) (2015) report a shortage of manufacturing workers as critical. And, like the HHS report, the nation's competitive economic edge is at risk of loss unless far more workers are trained. The agreed-upon solution to increasing the number of workers who possess the skill sets sought by industry is to maintain and create "more relevant education and training programs [with] an improved linkage between employers and education and training institutions” (p. 3).

Be it nursing or manufacturing, trade groups and organizations wishing to stem their respective critical shortage of skilled workers assert a solution lies within educational institutions and organizations and their capacity to turn out work-ready students. To be sure, nursing and manufacturing are not the only sectors facing a shortage of workers, but they are two areas about which I have had numerous conversations with individuals in those industries, and two areas of vital importance to the U.S. When a manufacturing plant closes, it often generates headlines and is featured on the nightly news. Likewise, if a hospital is not fully staffed and care becomes inadequate, the results are likely to become newsworthy.

If individuals charged with hiring new workers cannot muster the person-power needed to fill vacancies, then shortages will persist. Shortages prove problematic for at least two reasons: 1) worker shortages can prevent businesses from fulfilling orders or on-time work which can cause customers to look elsewhere, namely overseas; and, 2) vacancies can be filled with workers outside the U.S. who often work for lower wages which may elevate tensions between U.S. workers and their non-U.S. counterparts. In either case, the cause-and-effect relation between a lack of trained workers and potentially negative economic effects is undeniable. 
Today's calls from trade groups for workers with skills gained from CTE are reminiscent of when the National Commission on Excellence in Education's (1983) A Nation at Risk report menacingly informed the public a "rising tide of mediocrity" was set to hamper the U.S.' place of world prominence. A Nation at Risk warned the technological race was being lost and its authors called U.S. students ill-equipped for the knowledge economy, an accusation still mounted in the $21^{\text {st }}$ century. Although the authors called for a renewed emphasis on reading, writing, and arithmetic, the salient note is practical training and education was and still is seen as key to keeping the U.S.' competitive advantage and strong economy.

Trade groups like NAM and government agencies like HHS are not the only organizations that characterize educational institutions as part of the solution to training and educating the next wave of U.S. workers. University-based researchers also opine the U.S.' worldwide competitive advantage will be in peril if more is not done to stem the rising tide of the unskilled. Hamilton, Malin, and Hackmann (2015) warn reduced numbers of graduates in science, technology, engineering, and mathematics (STEM) fields will make it difficult "to maintain our nation's global competitiveness" (p. 29).

With the U.S. on track to become "minority white" in 2045 , if not before, a racially diverse workforce is inevitable and would seem vital to keeping the U.S. competitive (U.S. Census Bureau, 2018a). One area to explore how the number of students with technical skills might be increased resides within the U.S.' high school CTE programs. Students with an interest in fields like manufacturing and healthcare can begin career pathways in high school with hope the end of the path offers a job in their field of interest (Bragg, 2007; Hull, 2005). However, if students of color do not populate the beginnings of career pathways, a diverse workforce vital for maintaining and growing the economy will be elusive. CTE researchers find a lack of minorities 
and women exists in STEM career pathways today, but often analysis ends by when data was compiled and sorted into broad categories, often by race and gender, to make broad generalizations (Hamilton, Malin, \& Hackmann, 2015; Rojewski \& Xing, 2013). Career pathways remaining largely white need to be investigated in an effort to find root causes for the lack of people of color in those pathways. Researchers need to push beyond simple categorization to question how and why students, especially students of color, have come to end up in their respective career pathways.

\section{Career Pathways and Pipelines}

To educate and train the future workforce, particularly in nursing and manufacturing, many employers and trade groups view the U.S. community college system as both training centers for incumbent workers and sources through which they might locate and hire potential employees (Grubb, 1995). Because manufacturing jobs have a multiplier effect, this sector is

vital to explore. A multiplier effect occurs when a manufactured product spurs the manufacturing of other products. For instance, the market for cell-phone cases was generated because of the manufacturing and production of mobile phones. In addition to manufacturing, considering healthcare industry-related jobs is important because there are still many healthcare jobs that are difficult to outsource or offshore which is one reason industry organizations publish reports about critical worker shortages.

To keep community colleges' technical programs viable and fully enrolled, community college personnel look to secondary schools as program feeders, often creating articulation agreements between institutions so students can begin a technical course of study in high school and continue along that curriculum into community college (Hull, 2005). Coursework transitioning from high school to community college, called a career pathway, is designed to 
eliminate redundancies and course duplication for students in a chosen career pathway. As I document in Chapter Two, federal CTE funding requires the elimination of redundant coursework which makes examination of career pathways salient (U.S. Congress, 2006).

So vital is developing a pathway system designed to fill critical employment vacancies, the problem can make front-page news as it did in Rockford, Illinois when the Rockford Register Star published a front-page story noting a critical nursing shortage in the local community, which mirrored a national nursing shortage (Guerrero, 2016). Guerrero offers statistics qualifying the shortage, sharply focusing on an extreme shortage of nurses from underrepresented groups: “fewer than a quarter of the nation's 3 million nurses are racial or ethnic minorities, even though those groups make up 38 percent of the general population” ( $₫ 5$ ). According to U.S. Census Bureau (2015) data, today's so-called minority groups, chiefly people of color, "are projected to comprise 57 percent of the population in 2060" (\ 12). With people of color expected to become a majority of the U.S. population, communities like Rockford, a city with a high percentage of racially, culturally, and ethnically diverse citizens are attempting to ensure healthcare career pathways produce a nursing pool that will reduce the nursing shortage and more accurately reflect local population demographics.

To this end, Rockford's area community college, Rock Valley, partners with a local hospital to offer a healthcare career pathway that allows students to complete a bachelor's degree in nursing at the community college site (Rock Valley College, n.d.). The initiative-a growyour-own effort—is designed to create a reliable pipeline of local nurses recruited from the community.

U.S. Census Bureau (2018b) data show Rockford's population has $42 \%$ racial and ethnic minority members; the demographics of the city's school system show a higher percentage of 
students of color. Interactive Illinois Report Card data on Rockford Public Schools' student body reports: 31.6\% white, 30.6\% Black, 26.9\% Hispanic, 4\% Asian (Illinois State Board of Education, n.d.a.).

Given Rockford's large minority population (one inching close to majority status) in the secondary school system and community, and given the very public, critical healthcare worker shortage, the region is attempting to enact a reliable healthcare-career pathway through which students of color and those of ethnic minorities can advance and be directly linked to one of the numerous openings at local healthcare facilities.

As the Rockford nursing career pathway currently operates, the make-up of people who are in a nursing career pathway lies in stark contrast to the city's schools and the population's demographics. The Rockford Register Star reports the racial makeup of nurses at a representative Rockford hospital as $89 \%$ white (Guerrero, 2016). Although the front-page story I refer to earlier on the critical nursing shortage features a Latinx student on her journey toward becoming a nurse, her story comes across as documenting an outlier rather than demonstrating a system through which a diverse and highly qualified workforce reliably emerges. The overrepresentation of white workers in Rockford's local workforce, even with the city's overwhelmingly minority population, is called out in a subsequent Rockford Register Star Editorial Board op-ed that makes clear the pressing need for more women and minorities in areas like emergency services, namely firefighters and first responders. The Editorial Board does not mince words, stating unequivocally, “[Rockford] must do a better job of hiring people who look like Rockfordiansall of them” (Rockford Register Star Editorial Board, 2017, ๆ 6).

Since U.S. Census Bureau (2018a) demographic projections evidence "white” soon no longer will be the dominant racial group, CTE career pathways that result reliably in a heavily 
white workforce need analyzing by those who design and enact the nation's career and technical education system, specifically CTE educators and policymakers. Illinois public high school CTE enrollment data from the Illinois State Board of Education (ISBE) show white students to be overrepresented in most CTE career pathways (Hamilton, Malin, \& Hackmann, 2015). Instead of supplying a diverse workforce, current CTE pathways are instead filled by a white student majority.

As a current CTE faculty member and former administrator serving both secondary and post-secondary institutions, I am concerned by data reporting how some career pathways remain largely white. In my review of the literature, I document research showing CTE's disproportionate output of white students make CTE an education venue where students of color are unlikely to flourish, especially in career pathways leading to jobs earning a living wage with genuine opportunity for advancement. Healthcare careers provide a useful example illustrating what I mean by “advancement." A healthcare worker's career progression can begin with a student enrolling first in short courses to become a certified nursing assistant (CNA). After becoming a CNA, that professional can progress up the medical career ladder to become a registered nurse and even on to become a physician's assistant or doctor. I contrast this with service-sector jobs like those in the hospitality industry. While service-sector career pathway advancement opportunities exist, they do not offer nearly the same wage potential as those in healthcare (Torpey, 2015). While a worker may advance from a cook to a manager, the wage levels and advancements are not as robust as those in healthcare. Since CTE falls outside the purview of common core subjects like math and science, it is reasonable to expect enrollments strongly skewing white to be overlooked or cast aside as simply "the way things are" or outside the scope of interest for students of color and ethnic minority students. In order to expose, 
illuminate, and analyze inequities in Illinois' CTE career pathways, I therefore examine ISBE's CTE enrollment data collected from Illinois public high schools. Career pathways that admit and graduate largely white graduates, if left unchanged, will perpetuate a predominantly white workforce and deprive students of color career pathways with high wage potential.

\section{Statement of the Problem}

CTE teachers and administrators in the Illinois secondary school system may contribute to or uphold the current segregated labor market by advising white students into higher-skilled, higher-wage career pathways, especially those related to science, technology, engineering and math (STEM). Exposing inequities in Illinois' CTE system may inform and give pause to teachers and administrators who implicitly or explicitly steer students of color into low-wage, service-field career pathways that offer limited career opportunities.

Loeb et al. (2017) state simply, “descriptive analysis is data simplification” (p. 1). In Chapter Three, I report descriptive statistics on Illinois' CTE data to illustrate who enrolls in CTE courses in Illinois' public high schools and to what extent students of color are likely to be enrolled in a STEM career pathway. I use descriptive analysis to answer these questions because it helps researchers identify trends and reveal patterns previously unseen (Loeb, Dynarski, McFarland, Morris, Reardon, \& Reber, 2017). The outcomes of descriptive analysis can serve as a springboard for further research designed to reveal causal understandings and ultimately may generate strategies to build more equitable CTE pathways in Illinois. With over 200,000 CTE students enrolled in Illinois high schools, data are plentiful. I submit simplifying data to illustrate patterns make the findings I report in Chapter Four approachable to CTE teachers, administrators, and academic advisors. 


\section{Pairing Descriptive Statistical Analysis with Interpretivist Critical Re-Analysis}

My desire to reveal the story behind ISBE data using descriptive statistics more typically employed by post-positivist researchers whose "value-free, detached observations...offer explanation and...predictability" (Crotty, 1998, p. 67) is made methodologically unusual in this study by my desire to re-examine the data through a critical theory lens to reveal social inequities masked by descriptive analysis alone. By re-focusing on critical analysis from which to draw my study's findings and implications, I move sharply away from a post-positivist philosophy of science because my interpretations are not value free. Instead, I move toward a philosophy of science aligned with interpretivism—challenging conventional structures of CTE—in order to remain true to my belief in the transformative potential of CTE and the emancipatory aspects of careful critical research, a belief system firmly rooted in my experience as a CTE educator (Crotty, 1998).

As a participant in meetings where Illinois CTE enrollment data reliably have been used to make curricular and enrollment decisions affecting students, I began to question how CTE administrators could claim objectivity in their decision making. By claiming objectivity, people are free to claim their positions and personal backgrounds can be bracketed and set aside, having no discernable effect on data interpretation (Crotty, 1998). Because much data is disaggregated along gender and racial categories revealing stark differences, I submit a more critical approach is warranted in order to examine potential inequities. Instead, my philosophy of science aligns with an interpretivist approach more suited for considering "individual phenomena in order to trace their unique development" (Crotty, 1998, p. 68). Consistent with interpretivism's constructivist epistemology, I have no intention of generalizing my findings to the broader population. Furthermore, I make no claim to objectivity. By re-examining my descriptive 
analysis using a critical social theory lens, I maintain a primary focus on relationships across CTE career pathways to expose inequities which indicate students of color are not enrolled and may be routed away from CTE courses and career pathways with high wage potential — which effectively denies students of color the emancipatory potential of technical and higher education. By exposing patterns in Illinois public high school CTE enrollments, CTE advisors and faculty can examine their own practices and consider whether changes are warranted to make the CTE classroom a more welcoming space for students from all backgrounds.

\section{Impetus for the Study}

The inclination to research CTE enrollment and career pathways comes from my own personal experiences and curiosity as a CTE educator along with the long history practical and vocational education has had, and continues to have, with respect to national, state, and local policies and CTE's linkage to the labor market (Hayward \& Benson, 1993). It is not uncommon to find CTE's link to the labor market stated as a metaphorical pipeline flowing from secondary to post-secondary and flowing from post-secondary to a job (Barnett \& Bragg, 2006). The pipeline metaphor suggests a flow of students exists in a contained and controlled system. Once students enter a career pathway, employers at the end of the line turn on the tap to receive a flow of qualified workers. The CTE pipeline ideally transports a student from the secondary system into a job devoid of snags or obstacles along the way. If well-intentioned educators and industry representatives would truly like to see a more diverse talent pool emerging at the end of a career pathway, then an inspection to see why this does not now occur is in order. The inspection, however, should not focus solely on students who enter a career pathway. Because trade groups have a vested interest in obtaining qualified workers, influence from business and industry on a particular career pathway is usually seen as helpful (Bragg, 2007; Hull, 2005). This influence is 
problematic because, if left unchecked, business and industry representatives may become de facto arbiters of CTE curricula as well as CTE facts, leading to diminished personal agency for CTE educators and students, thus lessening the emancipatory power of education (Giroux, 2014).

My study is meant to assist educators critical of the growing neoliberal educational model taking hold in education by exposing career pathways that reinforce negative social stratification and inequitable curricula (Bourdieu \& Passeron, 1990). Equally, PK-20 decision-makers who use data to make policy decisions, especially in CTE, may find useful results exposing racial patterns demonstrating inequities within and across career pathways. This study, I propose, may also benefit educators who desire more racial and gender parity in CTE classrooms in an effort to stop the marginalization of students of color.

In order to begin to expose and evidence CTE enrollment patterns that may lead to inequities for students of color and maintain a status quo of white overrepresentation and privilege, in Chapter Two I examine legislation, both historical and current, which created what is now commonly referred to as CTE. Chronicling the timeline for CTE legislation sheds light on how policies designed to connect schools to business and industry were formed. These policies have been debated and continue to be debated especially with respect to the role of tracking in public education.

I describe and define topics like alignment and career clusters used by educators and policymakers in conjunction with career pathways as well as illustrate how the delivery of CTE creates an expectation of a linear path directly from high school CTE courses to a job. I also highlight how pro-business research on CTE keeps the field in a state where inequities, especially for students of color, often go unnoticed, unstudied, and unaddressed by current CTE instructors, counselors, academic advisors, and policymakers; unexamined practices can do harm 
by making the CTE field complicit in perpetuating an inequitable status quo (Rojewski \& Xing, 2013).

\section{Situating in the Literature}

I employ whiteness studies rather than Critical Race Theory as my theoretical frame with which to re-analyze my descriptive analyses in order to avoid the pitfall of appropriating theory situated in the experiences of people of color (Harris, 1993; Leonardo, 2002; McLaren, 2000). In Chapter Four, I use whiteness studies to make the findings of my descriptive analysis socially applicable to the CTE field and beyond and as a tool with which to study career pathways and unmask "the relationship among race, racism, and power" within those paths (Delgado \& Stefancic, 2012, p. 3). I anticipate results may assist teachers, counselors, academic advisers, and policymakers in recognizing how students who enroll in CTE may still be affected by "the central role racism play[s] in the structuring of school" (Solorzano \& Yosso, 2001, p. 3). Theoretical concepts I draw from whiteness studies allow me to question deep-seated, taken-forgranted norms about what type of students a teacher might expect to see in a CTE classroom. I then use my theoretical lens to create an alternate viewpoint which allows for color-conscious dialog on CTE (Bonilla-Silva, 2005; Ladson-Billings \& Tate, 1995).

By employing interpretivist critical analysis in order to push against positivist claims often associated with data-driven decision making, I aim to add to the body of literature by providing different ways educators can use CTE data to consider whether a discipline sets out to be equitable and delivers equity to all students. I pose my questions from an interpretivist rather than a post-positivist viewpoint, although post-positivism would be the theoretical paradigm or philosophy of science that typically underlies quantitative analysis and frames the truth and knowledge claims of quantitative research. Bringing a novel philosophy of science to bear on 
quantitative research on this phenomenon using whiteness studies as a critical tool of analysis I argue to be one of the significant contributions of my work.

Since race continues to play a central role in U.S. secondary schooling, displays of racial inequity require more than scant mention in research findings. Scholars who study secondary students' career paths and who consider race in their research treat race largely as one of a handful of buckets into which students are categorized (Rojewski \& Xing, 2013). In Chapter Two I review CTE research literature to illustrate how race has been used to group students. Once students are categorized there is a tendency to generalize findings to the population as a whole and summarize findings without subjecting analysis results to deeper questioning on why students fall into certain categories. Since CTE is a fluid part of school curricula in that CTE changes as technologies change, and because of this dynamic, I submit research into CTE requires analysis that goes beyond simple categorization. Using a critical interpretivist approach to re-analysis allows me to push against findings that would be considered objective in order to challenge CTE’s “conventional social structures” (Crotty, 1998, p. 157).

A convention prevalent in CTE research is the link between business' financial bottom lines and CTE. Without qualified technical people, businesses stand to become less profitable. CTE educators who can demonstrate a healthy link to business often view programs favorably (Bragg, 2005). However, when business motives are not questioned, CTE faculty may unknowingly abdicate curricular responsibility to the business sector.

As a practicing CTE educator, when business linkages with CTE programs are looked upon as essential to the success of CTE programs, such discourse raises my concern. Business partnerships can be positive but when those partnerships are not critically examined what can be missed "is any analysis of how power works in shaping knowledge, how the teaching of broader 
social values provides safeguards against turning citizen skills into simply training skills for the work place" (Giroux, 1999, p. 154).

\section{Research Questions}

To pursue my line of inquiry empirically, I ask the following questions of the Illinois public high school, secondary student CTE enrollment data obtained from the Illinois State Board of Education's College and Career Readiness Division:

1. Who enrolls in CTE courses in Illinois' public high schools?

2. How do patterns in CTE enrollment differ for students of color from their white counterparts?

3. Given patterns in course-taking, to what extent do students of color enroll in classes leading to STEM career pathways? 


\section{CHAPTER II: REVIEW OF THE LITERATURE}

\section{Introduction}

I bring a critical perspective to this study because I maintain "interrogating commonly held values and assumptions" (Crotty, 1998, p. 157) creates space for new meaning to be derived. Themes that emanate from the literature and I deem as important context for my work include the history and beginnings of CTE; policies on CTE, especially Perkins legislation which funds much of today's CTE programming; debates surrounding technical and liberal education as a way to advance people of color; the discipline's treatment of the topics race and equity; and the linkages between industry and CTE. I choose these themes because they create context for how CTE has been addressed and acted upon by policymakers over time. Moreover, because CTE has such strong linkages to industry-related skills, it is important to examine the literature for probusiness, neoliberal bias. Therefore, in this chapter I review both historical and current CTE research and identify gaps in the literature.

Since 1862, when U.S. Congress voted into law the Morrill Act, legislators have been making policies that have had profound effects on U.S. career and technical education institutions and students. Although CTE courses in today's secondary schools are typically electives - courses not usually required to satisfy graduation requirements—students who enroll in CTE courses can have either profoundly good or poor experiences. Learning a skill in a CTE class that ends up resulting in lifelong work for a student is often held up as a key reason for the

relevance of offering CTE in U.S. high schools. However, a student of color who is told her math skills preclude her from taking an introductory engineering course is likely to have a poor outlook on CTE's relevance (Gordon, 2008). The two ends of the CTE spectrum illustrate how fraught entrée into CTE career pathways can be and why it is critical educators delve into its 
history. Indeed, the history of CTE shows how it has been viewed either as an uplifting force for people of color or a force for keeping people of color in subservient economic roles.

Because I am interested in examining enrollment patterns, especially patterns among students of color, and the likelihood of students of color enrolling in CTE courses leading to prestigious career pathways like STEM, I submit it is important to consider the past performance of CTE policies so a historical perspective can inform today's CTE to ascertain if students in today's CTE courses find it is a system designed to assist their career aspirations or a system leading them to menial jobs with stagnant wages and diminished career opportunities.

\section{History of CTE}

The national debate about whether education should be liberal or technical began long before the "rising tide of mediocrity" in the U.S. educational system was noted in the National Commission on Excellence in Education's (1983) A Nation at Risk report. A salient point made by the report's authors - aside from the dismal performance of U.S. students relative to other countries in core curricular areas of reading and writing — is the need for a citizenry to have technical acumen in the computer age. This is important because $A$ Nation at Risk authors differentiate between core curricular areas and technical education. They maintain shoring up both areas, considered vital to the country's future and demonstrating the importance of technical education but also maintaining it as separate from core curricular areas. Although the authors do not use the term tracking, the distinctions drawn evidence two distinct tracks of education: core and technical. 


\section{Vocationalism}

CTE and vocational education or training are terms often interchanged, but there are researchers who qualify their use of the vernacular. Grubb and Lazerson (2004) refer to vocationalism as "an educational system whose purposes are dominated by preparation for economic roles" (p. 3). Noteworthy is the manner in which they consider vocationalism. They submit vocationalism is not about job skills. Rather, Grubb and Lazerson (2004) consider vocationalism to be broad in manner, encompassing "connections to greater society" (p. 3). I agree education can connect one to the greater society-hopefully lifting some boats along the way_ and that connection makes exploring CTE career pathways for potential inequities still relevant and still timely. These researchers also illuminate the role businesses and corporations have played in education, especially with respect to schools and universities meeting the education and training needs of industry, offering a cautionary note via Dewey's philosophy from over a century ago. Dewey's concern aptly sums up the downfall of educating for a specific need of business and industry:

Industry at the present time undergoes rapid and abrupt changes through the evolution of new inventions. New industries spring up, and old ones are revolutionized. Consequently, an attempt to train for too specific a mode of efficiency defeats its own purpose. When the occupation changes its methods, such individuals are left behind with even less ability to readjust themselves than if they had less definite training. (quoted in Grubb \& Lazerson, 2004, p. 9)

Curricula leading to the day's industry-recognized credential is likely to become obsolete and leave a student in a lurch when a newer, shiner credential replaces the dull, outmoded one. Dewey's thoughts align with DuBois' (1903) notion of the importance of providing a lasting 
education to the Talented Tenth of Black men, an education with staying power designed to help one lead his community.

Whether finding the correct balance between educating for the short-term, industryrecognized, pro-business purpose which will become outdated, or educating for the long-term and building equity-laden career pathways for the long-term is still being questioned today. Each have merits, and both are rooted in the early history of CTE.

\section{National Society for the Promotion of Industrial Education}

Policies and philosophical debates about vocational education and the roles of the secondary and postsecondary systems have a history that reaches back to the turn of the $20^{\text {th }}$ century. In 1906, the National Society for the Promotion of Industrial Education (NSPIE) was established to advocate for more technical education in the secondary system. Productivity gains in industry and agriculture as well as those needs arising from war production required a more skilled worker. Students with more practical and mechanical skills linked to industry were considered important to maintaining productivity gains. Business and industry lauded the NSPIE for its proposal that more industry-related skills be taught in schools. Educational tracks were developed to satisfy the needs of the economy and immigrant students or students from low socioeconomic status backgrounds were most often assigned to vocational tracks (Oakes, 2005; Urban \& Wagoner, 2014). "Vocational teachers emphasized job-specific skills to the almost complete exclusion of theoretical content. One result was that the intellectual development of vocational students tended to be limited at a relatively early age" (Hayward \& Benson, 1993, p. 8).

Modica (2015) asserts “academic tracking strengthen[s] racial boundary keeping” (p. 87). She observes students who are tracked into narrow educational paths seem to come to an 
acceptance that tracking and separating are a normal part of the school system. When any system or way of doing something seems natural, it becomes difficult to problematize or offer a contrarian viewpoint. Student tracking, as a result of career pathways, may therefore seem "natural" given the long history it has maintained in the educational system. Because of this history, detrimental effects of tracking like the lowering of one's own aspirations go unnoticed (Carter, 2012). Therefore, understanding the historical aspects of CTE serves in informing the future.

\section{Smith-Hughes ACT of 1917}

Eight years after NSPIE's founding, Congress codified vocational education policies by passing the Smith-Hughes Act of 1917. Monies were appropriated for promoting agricultural, trade, and industrial subjects as well as preparing vocational teachers (U.S. Congress, 1917). By providing funding at the secondary level, schools could offer a practical education which would provide students not bound for university an opportunity to obtain a skill and be of value to the labor market. Critics, most notably educational philosopher John Dewey, believed distilling a student's education down to a particular occupational skill robbed the student of the emancipatory power of education (Urban \& Wagoner, 2014). Critical scholars like Henry Giroux (2014) similarly argue students will be robbed of cultural capital and the ability to participate fully in society if led down narrow paths. A tracked career pathway—one with a rigid, prescriptive sequence of courses - takes away the profound social aspects of education and replaces them with a mechanized, non-flexible, "pedagogy of conformity" (Giroux, 2014, p. 29): a conformity that runs contrary to education's liberatory intent. While narrow paths focused on specific skills, such as running a lathe, have given way to a more nuanced, impressive-sounding, industry-recognized credential, constant and repeated calls for the education system to feed the 
people it needs to the business workforce remains (Soulé \& Warrick, 2015). This reinforces my assertion on the role education plays in preparing a workforce, by tracking students into specific career pathways, and underlining why it is important to examine critically career pathways since they are considered vital to the nation's economic health and growth.

When Congress passed the Smith-Hughes Act of 1917, the act provided funding for “trade, industrial, and agricultural subjects" for secondary schools as well as trade-like schools (U.S. Congress, 1917). One hundred years ago, as is the case today, secondary schools were seen as a feeder system for business and industry by providing a pipeline of workers. Today, although the types of manual training needed for a labor-intensive manufacturing economy have given way to soft-skill training for a knowledge-based economy, high schools and the students who attend them are still viewed as an important feeder for business and industry in an era of globalization (Andrade, 2016). For today's CTE teacher, it is important to understand that debates concerning education and whether high schools can provide industry with skilled workers are not new conversations. As in the past, concerns about education continue to be fueled by fear of the U.S. losing global economic prominence. The task of keeping the country competitive in the marketplace has been part of the educational landscape, especially of CTE, for over 100 years. Today's CTE educators and policymakers are no different than those of the past who try to respond to industry's repeated calls for more qualified workers in the hope of bringing the nation out of risk. Indeed, DuBois and Washington debated one another on the role technical education should play in the lives of people of color. 


\section{DuBois and Washington Debate Manual Training}

When considering the history of CTE, especially when racial equity is invoked, it is appropriate to consider W.E.B. DuBois' and Booker T. Washington's early debate of the merits of manual training and whether manual training tracked and kept Black people in subservient positions or whether a sense of agency resulted. Their debates serve as reminder of the limits of meritocracy, a gap I see in today's literature. Current educational literature and research rarely question meritocratic notions (Bryerton, 2016; Mijs, 2016), the likes of which undergird the trope of The American Dream and mythical poor-boy-makes-good stories in the genre of Horatio Alger. If, in current times, the potential to use CTE courses to track students of color into roles and careers which relegate them to a lower status than white students still exists, the debate between Washington and DuBois is vital to keep fresh. If, in the case of CTE, it seems history is in danger of repeating itself, it is crucial to understand and offer remedies and policies that remake CTE to become the rising tide capable of lifting all boats.

DuBois (1903) claimed continuing a more liberal-arts-focused education for the Talented Tenth of Black men would elevate them and begin to create an atmosphere where they could offer their own truth and knowledge claims to larger society. DuBois wanted to create a Black intellectual capacity that could push back on white domination. He worried that if Black people were given only vocational training, it would surely stigmatize and keep them in service-focused, subservient roles especially since they still lacked the right to vote, a key reason he disagreed with Washington.

Washington saw vocational education as a way to help Black communities thrive by not having to rely upon white business owners for job creation and growth. Black people who learned a trade would become the Black community's business leaders and help maintain a 
vibrant Black community, such as the prosperous Black neighborhood DuBois called the "Black Wall Street" of Tulsa, Oklahoma. In addition to growing the strength of Black communities, Black tradesmen would be available to do work white people needed. In this way, Washington figured Black people, many of whom were former slaves moved north to find industrial work, would become a vital part of society and steadily make economic and social progress. Although Washington's major argument (1903) differed vastly from DuBois', he too framed education, specifically vocational education, as a path to improvement. My purpose in bringing Washington and Dubois' debate to my readers' attention is not to warrant further exploration into DuBois' and Washington's debates, but to highlight how many Black people of the time felt strongly that Washington's view was accommodating to white people and perpetuated, if not manufactured, what whites wanted: a permanent Black lower class to do work white people did not want to perform. Today, the dearth of nurses of color illustrates how the debates of DuBois and Washington are still relevant today and warrant robust investigation into the state of today's CTE system.

\section{The Vocational Education Act of 1963 and Title IX}

DuBois and Washington were not the only scholars concerned about the relationship between racial equity and vocational education. U.S. Congress (1963), under the Kennedy Administration, passed The Vocational Education Act of 1963 authorizing funding for vocational work-study programs, and mandating equity become a programmatic focus. The programs were designed to provide a service industry-readied workforce to help maintain the nation's preeminence as manufacturing juggernaut. High school CTE programs were looked at as a vital part of the U.S. economic engine and having a focus on equity would help ensure access to programs was fair. 
President Johnson's “war on poverty” was designed to assure good jobs which meant vocational education was a focus and the new legislation mandated gender equity be part of programs so people of color were not further marginalized (Hayward \& Benson, 1993; U.S. Congress, 1963). Equity was a concern when Congress (1976) passed the Education Amendments of 1976, now often referred to simply as Title IX, which sought the elimination of sex bias and sex stereotyping. Programs were thereafter to be instituted in ways that prevented discriminatory practices from taking root in education. The 1976 amendments also authorized the National Assessment of Vocational Education (NAVE), completed in 1980, which led to the creation of the Carl D. Perkins Vocational Education Act of 1984. Perkins is still the major piece of legislation today which stipulates parameters for CTE programs, including the mandated reporting of programs' racial demographics (U.S. Congress, 2006).

\section{Perkins Act}

Perkins and its subsequent reauthorizations continue to refine the role secondary and postsecondary schools play with respect to CTE, workforce preparation, and technical training (Lewis \& Cheng, 2006). Moreover, because Perkins legislation is the mechanism through which CTE programs in secondary and post-secondary institutions are funded, debates about how CTE affects students and whether it is a tracking mechanism are still active and relevant. For over a century_-beginning with the Smith Hughes Act in 1917 and now with current-day Perkins IVeducation and its ability both to prepare students for a changing work world and the resulting standing the U.S. maintains in the global economy remain constant concerns of policymakers and researchers.

Perkins IV continues to keep CTE in the forefront of current policy and Perkins IV mandates institutions receiving funds track and record performance indicators (U.S. Congress, 
2006). Institutions must track "student attainment of career and technical skill proficiencies, including student achievement on technical assessments, that are aligned with industryrecognized standards" (p. 14). The role of secondary schools and their ability to provide an educated workforce for the business community is still a central concern for practitioners, businesses, and policymakers and illustrates how the linkage between policy making, schooling, and business remains alive and well.

From the inception of the Smith-Hughes Act, passionate philosophical debates between Washington and DuBois, and current regulations under Perkins, rhetoric continues to swirl around education and the role it plays in keeping the U.S. globally competitive. Perkins legislation is important to consider because it codifies the pathway model for CTE and provides other organizing principles that shape CTE today.

\section{Program of Study (PoS), Career Pathways, and Career Clusters}

Legislation and policies surrounding CTE indicate it is more than just courses a student takes in high school. The connections between secondary and postsecondary educational institutions and employer-based training encompass a wide variety of services for students interested in certain career pathways. For instance, internships might be available to students who enroll in specific courses. CTE infrastructure has been built utilizing pathways, alignments, clusters, and programs of study which give the illusion CTE is capable of providing students who follow a linear, prescribed path with a career. The ideal path starts with a high school CTE program, moves through non-duplicating courses at the post-secondary level, and ultimately leads to a job. In order to create an ideal path for a CTE student, many things need correctly to align. Agreements between institutions need to be valid, courses need to be current, and timing needs to work for the student. Working toward an ideal is noble but it is unrealistic to think the 
ideal can be met every time for every student. In an effort to create the best environment for career pathways success, U.S. legislators who crafted Perkins legislation developed programs of study (U.S. Department of Education, 2006).

Programs of Study (PoS) and career pathways are covered by the umbrella term Career Clusters, which illustrate how groupings of CTE courses fit into the larger context of a particular occupational field. States, school districts, and faculty base CTE course sequencing around respective Career Clusters. For instance, a finance cluster PoS offers appropriate courses in which secondary students can enroll that have the potential to lead to post-secondary instruction with the least amount of duplication (see Appendix B for a PoS example). Career Clusters, of which there are 16, range from agriculture to finance to STEM (Advance CTE, 2007). Career Clusters fit into a wider framework of labor information called O*NET. The O*NET database, sponsored by the U.S. Department of Labor/Employment and Training Administration (USDOL/ETA), contains occupational descriptors along with the skills required for one to work in a particular occupation. Descriptors are cataloged by way of the Standard Occupational Classification (SOC) and linked to the Classification of Instructional Programs (CIP) number. Illinois State Board of Education (ISBE) secondary and post-secondary CTE enrollment data includes the number of students in a particular CIP. Because the CIPs, reported by ISBE, are connected to the Department of Labor and federal funding, the salience of deeply examining enrollment data for the purposes of casting light on potential inequities serves policymakers and practitioners who wish to keep equity at the forefront of their decision-making processes. 


\begin{abstract}
Alignment
I use the term linear to describe how policymakers and practitioners historically have conceptualized the school-to-work pipeline (Deloitte, 2015). I assert policymakers view CTE as a series of inputs and outputs: input the correct courses and education on one end of the equation and the output emerging from the other end is a job or entrance into an occupation closely aligned with the inputs, much like PoS plan outcomes put forth by Advance CTE (2017). I argue understanding how policies mandate this linear approach has relevancy because linearity evokes the idea of a smooth, straight graph-line free from susceptibility to much interference.
\end{abstract}

Alignment is the process by which courses are built on other courses from the secondary to post-secondary levels, and sometimes into business and industry. Perkins IV (U.S. Congress, 2006) codifies this alignment legislatively by spelling out requirements of articulation agreements "designed to provide students with a non-duplicative sequence of progressive achievement leading to technical skill proficiency, a credential, a certificate, or a degree” (p. 4). For example, a student enrolled in a first computer programming course would continue her or his studies beyond high school by enrolling in the second-level computer programming course. As the student transitions from high school to post-secondary, according to Perkins legislation, the student should not encounter duplicate course material (U. S. Congress, 2006). Furthermore, topics covered are intended to align with a starting skill set employers seek in a particular occupation (Hull, 2005). Career pathways starting at the secondary level where students then matriculate to post-secondary courses are not new. The American Association of Community Colleges (1984) branded an initiative "Putting America Back to Work" in which two-plus-two programs were outlined as a way to eliminate training redundancy in order to bring a welltrained worker to the marketplace more quickly. Two-plus-two means students spend two years 
learning specific technical fundamentals in the secondary system and add two more years of training in a postsecondary location. With Perkins IV in force, it is important the CTE instructor recognize CTE courses in which students enroll are intended to lead to more than just the end of a semester; they are intended as part of a pathway leading to future courses and occupational placements and CTE instructors should recognize they have a responsibility to students embarking upon career pathways.

\section{Credentials}

In addition to policies stating CTE courses should align between secondary and postsecondary contexts, industry-recognized credentials are an expectation of policymakers and employers. ISBE (2016b) documents show a list of credentials employers request in the state of Illinois. The listing of credentials is part and parcel of the way Perkins IV requires states to offer programs of study that "lead to an industry-recognized credential or certificate at the postsecondary level, or an associate or baccalaureate degree" (U.S. Congress, 2006, p. 57). However, credentialing in academia has been in existence for some time. Collins's (1979) work is worth noting because he warns of competition among institutions leading to credential inflation, a type of credentialing arms-race, important because if educational institutions enter into a credentialing arms-race, a hyper-competitive situation between institutions will arise. Students will then choose schools and programs for the cachet credentials provide in the job market rather than choosing an institution for what they can learn.

ISBE (2016b) publishes the number of credentials earned by CTE students in various career pathways. As credentials are more widely publicized, entities outside education, like government and business, expect educational institutions to create career paths, offer credentials, and provide seamless transitions along career pathways (Bankston, 2011). Extolling the benefits 
of third-party credentials endorsed by business is a way CTE department leaders signal their program's relevance (Collins, 1979; Kowalski \& Lasley, 2009). Departments and schools illustrate the strong link between curriculum and business and allude to a likely return on investment (ROI) on which the student may count. I assert using a return-on-investment model to justify an educational program is problematic for the institution and ultimately harms the student and keeps schools in a subservient position to business and industry. When a program is dependent upon business or industry for its relevance, the institution and the industry it serves become the arbiter of truth and knowledge claims and able to keep a handle on power and on what is produced. When knowledge is deemed obsolete due to changes in the marketplace, new truths will be offered and inserted into curricula allowing industry to claim expertise in curriculum and credentials and be rendered immune from culpability when students flounder because the "market" changes (Mantzoukas, 2007). In this scenario the blame then falls upon the individual when he or she does not or cannot turn their education into a high-paying job, blaming the student for choosing "unwisely." In this study I focus on the structure of CTE and how that may influence students who enroll in CTE courses rather than on students' decision-making.

The U.S. Department of Labor (DOL) (n.d.) extols the benefits offered by stackable credentials: "credentials can be accumulated over time to build up an individual's qualifications and help them to move along a career pathway or up a career ladder to different and potentially higher paying jobs" (p. 1). President Obama’s (2009) American Graduation Initiative (AGI) calls for a strengthening of the nation's community colleges by enabling five million more U.S. workers to earn credentials in the form of degrees or certificates. As a result of earning new credentials, the U.S. allegedly will be able to maintain economic preeminence. Since the president's initiative requires degree completion, it requires colleges use data to track students in 
specific certificate and degree programs. Perez and Copenhaver (1998) highlight the proliferation of coursework bundled into skills-based certificates as an indication of their legitimacy and value in CTE. By examining CTE enrollment patterns and the likelihood of students of color entering prestigious, high-wage pathways, I can examine who enters a pathway, especially STEM pathways, to offer descriptive statistics detailing career pathways leading to credentials and examine whether a pathway has majority white students and upholds the status quo or if students of color are fully represented in an equitable pathway.

\section{STEM Career Pathways}

Current CTE literature repeats old mantras about how the nation's ability to remain economically competitive is tied to schooling, and STEM career pathways are noted with particular interest (Asunda, Kim, \& Westberry, 2015; Hamilton, Malin, \& Hackmann, 2015). The average pay for people who enter into STEM occupations, according to 2015 BLS data, is almost double that of non-STEM occupations: $\$ 87,570$ versus $\$ 45,700$ respectively. STEM, though not a credential, nevertheless carries the characteristics of one and seems to be held in high regard among policymakers and researchers (Asunda, Kim, \& Westberry, 2015; Hamilton, Malin, \& Hackmann, 2015; U.S. DOE NCES, 2016). The U.S. Department of Labor (2016) claims jobs positioned to grow the fastest during the next eight years require postsecondary education for entry. Though this figure includes jobs requiring master's and doctoral degrees, jobs requiring an associate's degree are expected to grow $18 \%$. Consequently, career pathways leading to credentials in STEM-related occupations are highly valued. Students who enter STEM pathways have a higher potential for self-sufficiency because earning potential is greater. If the potential for self-sufficiency is greater for white students than students of color, diminished earning potential has a cascading effect; one's ability to move to a new geographic location is 
thwarted and occupational opportunities like internships can dim. If students enrolled in CTE courses are to become self-sufficient, it is important to consider race in CTE to ensure opportunities are reliably available to students of color, not just white students. Equally important is how the myth of meritocracy manifests within CTE. I maintain the current literature largely leaves out technical education's meritocratic principles. An assumption that merit is justly bestowed also assumes students in CTE, irrespective of race, enter on a level playing field.

\section{Race in CTE Literature}

Race in CTE literature is often noted as a way to group students who take a particular course, providing a snapshot in time that does little to examine CTE's systemic inequities (Lewis \& Cheng, 2006). Without looking more deeply into the racial demographics of career pathways, CTE instructors and administrators may be using pathways to track students of color into lowprestige, service-oriented career pathways. Rojewski and Xing (2013) are overt in their assertion race must be considered when researching CTE. They argue a lack of specificity about race in CTE can lead to assumptions based on deficit-based perspectives. The authors examine recent CTE studies to illuminate how race/ethnicity are addressed in the literature. From the 71 publications that met their criteria, they find only $25 \%$ of studies report race/ethnicity in the makeup of their samples. Rojewski \& Xing (2013) call for future CTE studies to put an emphasis on exploring race so research results might be generalizable to the populations in the respective studies. I am encouraged by their suggestions to challenge CTE researchers to set aside colorblindness, but their emphasis on generalizability of results manufactures missed opportunities to see students as unique and complex individuals. Critically re-examining CTE enrollment patterns through an interpretivist frame will help ensure the essentializing of students of color in CTE research is mitigated because "critical inquiry keeps the spotlight on power 
relationships within society so as to expose the forces of hegemony and injustice" (Crotty, 1998, p. 157).

Even when race and ethnicity are brought up in a critical light, most CTE researchers do little to question the motives of business relationships to career pathways. Hull (2005) offers up the neoliberal agenda as a sort of natural order. He suggests, "we expand our postsecondary investments in ways that yield the best possible results in the international marketplace" (p. 46). I offer this line of reasoning offers little to serve the hopes and motivations of students, rather it serves to perpetuate the neoliberalization of education (Bowles \& Gintis, 1976; Giroux, 2014). Representatives of business and industry who link up with CTE teachers and administrators are often looked upon as benevolent agents acting for the good of students. Focus is often on the relevance of the CTE program relative to the employer's wants and needs rather than economic motives (Bragg, 2005). When CTE teachers and administrators base their relevance on employer desires, they cede their curricular power to those outside of education.

The bottom line of the institution and of business is never viewed with the least bit of skepticism. Rather alarmingly, instead this relationship is viewed as the "best" way for career pathways to be effective. Looking at career pathways from a critical perspective must be initiated and studied in order to question thoughtfully the prevalent notion of business motives as benign and beneficial to the CTE system.

\section{Conclusion}

Perkins legislations requires states using federal monies to report annually on core CTE indicators of performance. "States are also required to report disaggregated data on the performance of students by race, ethnicity, gender, and special population categories" (U.S. Department of Education Office of Career, Technical, and Adult Education, Division of 
Academic and Technical Education, n.d., \ 1). CTE researchers use data in applicable ways like presenting the number of females or racial make-up of a particular CTE course or program of study (Bragg, 2007; DeFeo, 2015; Lewis \& Cheng, 2006; Rojewski \& Xing, 2013). Certainly, this can be useful for practitioners and policymakers who desire a way to generalize coursetaking patterns of CTE students, but it does little to question potentially unjust and inequitable institutional structures. Hamilton, Malin, and Hackmann (2015) contribute by questioning gender bias within CTE, encouraging practitioners to bring equity to the fore when considering CTE programming. Research like theirs holds promise because it begins to explore deep-seated norms that hinder a student's sense of agency. However, I submit it does not go far enough in its critical analysis. CTE researchers who examine race do so in a manner beholden to the theme of keeping the U.S. competitive in the marketplace (Bragg, 2005; Carnevale, Jayasundera, \& Hanson, 2012; Hamilton, Malin, \& Hackmann, 2015; Lewis \& Cheng, 2006; Rojewski \& Xing, 2013). Perhaps because of CTE's insular nature, apart from its core curricula few CTE scholars draw from social theory or employ critical analysis to dive below the surface of accepted norms to explore the depths of inequities still present in educational institutions, meaning a gap in the literature persists when it comes to examining CTE from a critical perspective focusing on equity and inclusion. Statements about keeping the U.S. economy competitive overshadow the plight of students of color in CTE. I intend my study to begin to fill that gap. 


\section{CHAPTER III: METHODOLOGY}

\section{Research Design}

In this study, I utilized a quantitative, descriptive research design to identify enrollment patterns of Illinois, public high school CTE students during the 2015-2016 school year. I chose descriptive analysis because it allows me to articulate patterns within the data. Because I was interested in who enrolls in CTE and in what courses they enroll, descriptive analysis makes it possible to paint the big picture of CTE in Illinois public high schools and identify issues for CTE teachers, administrators, and academic advisors to consider. Since I did not apply any type of intervention in this study, causal research methods were not paramount to the design. The descriptive work conducted allowed me to identify characteristics of the Illinois CTE student population. Because I looked only at Illinois' data, my findings are localized. Put another way, the results my descriptive analysis yields are specific to Illinois and not intended to describe CTE generally. My choice of descriptive research makes it possible to "distill the dataset into meaningful dimensions to uncover patterns and inform and improve decision-making" (Loeb et al., 2017, p. 3). My methodological choices rely upon descriptive statistics' ability to simplify complex data. It is my hope Illinois CTE administrators who use Illinois CTE data for making program decisions find the data I present quite usable.

Unique to this study is my choice to analyze ISBE data using quantitative statistical analysis, then, applying an Interpretivist theoretical perspective, I use a theoretical frame through which critically to re-analyze the descriptive analysis. I use descriptive analysis to identify enrollment patterns, which I judge to have significance relative to the literature on CTE coupled with my years of being a high school CTE teacher. I glean deeper meaning from the descriptive analysis outcomes by using a theoretical frame that allows me to reveal truths about the data that 
are only visible when viewed through the critical lens of whiteness studies and other theoretical concepts. Re-analyzing the descriptive analysis makes visible racial inequities and other social systems at work that constrain the CTE experience for some underrepresented students. What spurred my re-analysis were moments in my career where I witnessed CTE administrators who made broad generalizations about students of color based on enrollment data. For instance, at one meeting administrators noted the lack of Latinx students in CTE was due to Latinx students moving often between residences. Their uninformed, harmful stereotype of Latinx students in CTE programs galvanized my resolve to move away from analysis construed as objectivist (Crotty, 1998). Consequently, my overarching methodological intent in this study is not to attempt to validate "knowledge to what can be verified statistically" (Crotty, 1998, p. 131) but to use descriptive analysis to identify patterns meaningful for CTE practitioners and then critically to challenge the conventional, even stereotypical ways those patterns could be viewed. I want further to analyze and present data that shows how students of color can easily be marginalized, perhaps without CTE teachers, administrators, and academic advisors being fully aware. My analysis allows me to challenge the educational myth of meritocracy that underlies CTE.

\section{Data-Set General Characteristics}

The data set, obtained from ISBE's College and Career Readiness Division, includes over 200,000 enrollments from over 800 public school districts. The data is not merely a representative sample, it reflects the precise number of CTE students in Illinois enrolled during the 2015-2016 school year. I utilized the data available to me at the onset of the study. Because it reflects Illinois' full population of CTE students, the data has significant statistical power (Vogt, 2007). A student's year in school, the title of the CTE course in which the student enrolls, the student's race and gender, the school's CTE region, and Perkins core indicators were 
included. Perkins indicators are developed between the state and the federal government. States that do not meet indicators risk losing portions of federal funding (U.S. Congress, 2006). A complete list of data categories appears in Appendix A.

Each school's course enrollment data was uploaded by individual, Illinois public school districts and sent to ISBE for use in its Student Information System (SIS). Data assurance - that data sent to ISBE was accurate - was conducted by ISBE. If data from a particular school was dramatically different than its previous years, discussions between ISBE representatives and school representatives took place to verify the data's accuracy. As a former submitter of Perkins data to the state, I communicated with ISBE about anomalies that appeared in the data I was in charge of sending. Once anomalies were explained and no further data needed to be submitted, ISBE analysts compiled, extracted, and emailed data to me as a delimited text file. The file was imported into IBM SPSS Statistics version 24 with which I conducted statistical analyses.

In all my analyses the variables and their corresponding definitions were defined by the Illinois State Board of Education, save for the variable "STEM," which I created. Variables were in place when I received the data set and, other than the STEM addition and recoding of race for purposes of further analysis, the variables remain unchanged. Location was recoded $[0=$ Chicago, 1 = All Others] when considering enrollment patterns outside Chicago. If funding is tied to Perkins Core performance indicators, educators and policymakers will be familiar with the metrics by which performance might be judged.

Course enrollments and their corresponding titles range from agriculture to welding and represent the wide range of courses available to CTE enrollees. Location information offers the ability to consider enrollment patterns by settings, such as urban, rural, or suburban. Student characteristics like race, gender, and special population—data used for Perkins IV reporting 
purposes - provides a more granular look into specific student attributes to consider patterns based on factors such as whether a student receives free lunch or is enrolled in a STEM course.

I added a variable, STEM, because CTE literature authors reliably note STEM-related career pathways as ones of promise, often yielding higher wages (Asunda, Kim, \& Westberry, 2015) and upward, career-advancement opportunity. To determine whether a course was noted as "STEM" or "not STEM," I consulted the U.S. Department of Labor's Bureau of Labor Statistics (Torpey, 2015) to determine the types of occupations that fall under the label. Based on BLS categories, I judged by a course's title. STEM courses are denoted as $1=\mathrm{STEM}$ and $0=$ Not STEM.

\section{Levels of Analyses}

I utilized three levels of statistical analysis: univariate, bivariate, and multivariate. These analytic strategies allow me to answer the research questions I pose of the data and to do so in an orderly progression where each progressive step built upon the previous one and provided a means to examine general patterns as well as to funnel-down and tease out more specific ones. I was able to use "outlier" data that would normally be thrown out or explained away to create a normal distribution. Re-analysis using a critical, interpretivist lens allows the phenomenon to be considered deeply without making claims of generalizability or objectivity and without negating my own standpoint from which I approach the data (Patton, 2002). My research methodology, analysis, and re-analysis are designed to examine both aggregate and disaggregated data. The aggregate data illuminates the whole of Illinois CTE while the disaggregated data allow me to investigate data points that reveal areas of CTE that appear beneficial for students of color and a single area that showed exclusion of students of color. The following statistical analyses were run on ISBE data. 


\section{Univariate Analysis}

Using SPSS version 24, I ran descriptive statistics which yielded total enrollment for CTE courses, the number of males and females in each course, and the number of students in each course by race. Descriptive statistics are used to organize data in a manner which addresses my research questions about students of color's enrollment patterns in light of Illinois CTE students' entire population attending public high schools during the time period examined. Because I did not set out to compare the means of two or more groups, descriptive statistical analysis was appropriate (Vogt, 2007). Running descriptive statistics casts light on who is enrolled in CTE classes, while data re-analysis using a critical theoretical lens makes possible a way to consider patterns related to equity perhaps previously unseen (Loeb et al., 2017).

Descriptive statistics on course, race, gender, and whether a student receives free-or-reduced lunch (FRL) helped to answer my first research question: Who enrolls in CTE courses in Illinois public high schools? Descriptive analysis reveals the course names in which most CTE students enroll. Although descriptive statistics do not allow me to surmise why students enroll in particular courses, enrollment pattern variation is evidenced between white students and students of color. Moreover, descriptive output provides information that aligns with what authors of CTE-based research reveal: despite Illinois high schools' demographics, many CTE courses maintain a white majority. I then examined enrollment patterns of white students and students of color to consider how early segregation in CTE courses affects workplace demographics (Asunda, Kim, \& Westberry, 2015; Bragg, 2007; Hamilton, Malin, \& Hackmann, 2015). As I reveal in my re-analysis employing theoretical concepts from whiteness studies as my lens, how students come to be enrolled in CTE courses can no longer be viewed as politically or 
pedagogically neutral (Harris, 1993). Critical re-analysis allows me to question race- and classbased power relationships at work in today's CTE system.

\section{Bivariate Analysis}

To be able to provide statistical analysis that can assist university-based researchers interested in socially important patterns in CTE data, I ran bivariate analysis cross tabulations. I utilized cross tabulations to be able to describe more fully the relationship between two categorical variables since cross tabulations show both course and enrollment information. For this study, categories include: course name, STEM/non-STEM course classification, and students' race, gender, and free-and-reduced-lunch status. Students who qualify for free-andreduced lunch are often students of color (U.S. Department of Education National Center for Education Statistics, 2019). By using this category, I posit it helps display the overlapping and interdependent systems of discrimination.

Using two variables provides a more detailed picture of CTE-course-taking patterns of students of color and their white peers. Cross tabulations relative to my second question- $-\mathrm{How}$ do patterns in enrollment in CTE courses differ for students of color versus their white counterparts? - allow me to consider whether patterns of privilege are reproduced and whether they afford white students more opportunity to enter into more-prestigious career paths (McLaren, 2000). This form of analysis offers insights aligning with Hamilton, Malin, and Hackmann's (2015) research analyzing CTE enrollment patterns. Cross tabulations make possible comparison of relationships between two variables, but I also required a method that could provide predictive capabilities. 


\section{Multivariable Analysis/Logistic Regression}

The data set's large $n$ made it possible to run predictive models to consider the likelihood students of color would enroll in courses leading to a prestigious career pathway like STEM. In this stage of statistical analysis, I used logistic regression since the dependent variable is categorical (Vogt, 2007). This level of analysis aptly serves as a way to explore whether CTE is likely to reproduce social stratification where students of color are led into less-prestigious pathways while their white peers are led into more-prestigious ones. This analysis method helped answer the third question I posed of the data: Given the patterns in course-taking, to what extent do students of color enroll in classes leading to STEM career pathways? I set out to funnel my analysis down from one research question to the next, looking broadly at enrollment patterns and then narrowing down my focus with each subsequent question. To answer my third question, I ran a model to determine the odds ratio of a student of color entering a STEM career pathway to illustrate how descriptive statistics are useful tools to uncover patterns and to direct the researcher toward causal understanding (Loeb et al., 2017). Additionally, this level of analysis situated my study within the CTE literature (Dadgar \& Weiss, 2012; Grubb, 1995; Kerckhoff \& Bell, 1998). To run the model, I used STEM as my dependent variable. Course titles which aligned with the Bureau of Labor Statistics (Torpey, 2015) STEM occupations were coded "1" while those not aligned were coded “ 0. ." Independent variables race, gender, and free-andreduced-lunch were added to the model.

\section{Limitations}

It is important for any researcher to consider limitations and data accuracy (Vogt, 2007). I received my data set directly from ISBE which uses data, as required by Perkins legislation, to report the number of Illinois high school students enrolled in CTE courses and programs. During 
the course of this study, Perkins IV legislation was in force. Since completing my analysis and write up, Perkins V legislation was enacted and passed. Therefore, my study has the limitation that data was gathered and analyzed under a version of legislation now longer in effect.

ISBE data is often exported from school districts' information systems, so subject to human error. Students can be misidentified, miscounted, and omitted as a result of improper data entry. Without verifying individual-school-level data it is possible my data set includes inaccuracies that can neither be avoided nor remedied without considerable cost.

In addition to reporting enrollment data, Illinois high schools' CTE programs are required to obtain Illinois State Board of Education approval for CTE courses and programs for programs to be eligible to receive Perkins funding. Secondary-level instruction must align with CIP codes published by the U.S. Bureau of Labor Statistics (Illinois State Board of Education, n.d.b). Over time, it is possible for classroom instruction to become misaligned with the corresponding CIP code. As a result, my course-level analysis might not take into account actual instruction taking place in a high school classroom. In order to illuminate any misalignment, future researchers may opt to provide CIP code descriptions to high school CTE instructors, asking they rank how closely instruction aligns to CIP codes. In doing so, future researchers might better be able to assess course effectiveness knowing inputs like subject content are aligned to CIP codes.

While there is a great deal to be learned from large, public data sets like the one used in this study, I argue school officials and CTE-linked industry supporters remain in positions of power and serve as arbiters of truth and knowledge claims because students have little in the way of bargaining chips or space at the table. By not having student voices be part of my analyses, the depth and complexity of student voices and their experiences are missing here. Voices of CTE teachers, school administrators, students of color, their families, and community members would 
provide much thicker description and corresponding insight of what goes on in today's CTE classrooms and the implications.

\section{Theoretical Frame}

In order to understand more deeply the implications of recent Illinois CTE enrollment patterns I re-analyze descriptive statistical output using a grouping concept coined by theorists of Critical Whiteness Studies (CWS) (Harris, 1993; Ladson-Billings \& Tate, 1995; Leonardo, 2002; McLaren, 2000; Matias, Henry, \& Darland, 2017) as my theoretical frame or lens. Because policymakers and some university researchers view CTE as the type of education and training capable of maintaining the U.S.' economic preeminence, and because CTE reliably is positioned as a major step in upward-social-class mobility made plausible by higher education's meritocratic promise, I maintain examination of CTE using a critical theoretical lens is essential both to understanding the localized phenomenon and addressing those questions I pose of the data (Bragg, 2005; Carnevale, Jayasundera, \& Hanson, 2012; Hamilton, Malin, \& Hackmann, 2015). Entrusting U.S. prosperity to CTE system students and practitioners heaps undue responsibility on high schools in particular, so, as a result, I submit high school CTE enrollment patterns should be analyzed to determine whether data shows students of color sorted systematically into low-skill career pathways as consistent with those who theorize classic educational social reproduction. As Bowles and Gintis (1976) seminally argue, "the major aspects of education replicate the relationships of dominance and subordination in the economic

sphere" (p. 125). So, to follow the logic of CTE's transformational pedagogical and meritocratic claims when viewed in light of social reproduction theory, if CTE high school students are socialized into habits associated with their likely position in the hierarchical division of labor, 
not only will social stratification be reproduced when students enter the workforce, but social stratification actively is being engineered pedagogically within CTE institutions.

\section{Critical Whiteness Studies}

To explain the branch of social theory and specific theoretical concepts I have chosen to use as my theoretical frame, I first turn to the task of defining the trope "white." When white people use the word "white," for many this term evokes skin tone, or for a few it may refer to a personal colonial origin story, but, as Ta-Nehisi Coates (2015) contends, at is most base meaning, "white" represents "the belief in the preeminence of hue and hair" (p. 6) — that is to say claiming the label "white" means a person takes a place of political and cultural prominence, thereafter able to exert power over those who cannot claim the powerful label "white." Coates succinctly explains this seized, elevated status initially was not freely given, rather he theorizes this status has to be taken. Even more important to recognize, the label "white" is an invented racial distinction and its membership has changed drastically as groups rendered formerly savage, such as Eastern European immigrants, were welcomed into the fold of whiteness, increasing the sociopolitical power of the label "white." The label "white" grew in power in direct response to the post-bellum Black migration north, to the U.S. civil rights movement and its victories, to the desegregation of schools, and, now, to the imagined "rising tide" of brown immigrants and asylum-seekers. Coates succinctly, powerfully theorizes the manufacture and growth of "white," made all the more significant because...

Americans believe in the reality of "race" as a defined, indubitable feature of the natural world. Racism - the need to ascribe bone-deep features to people and then humiliate, reduce, and destroy them - inevitably follows from this inalterable condition. ... But race is the child of racism, not the father. And the process of naming "the people" has never 
been a matter of genealogy and physiognomy so much as one of hierarchy. Difference in hue and hair is old. But the belief in the preeminence of hue and hair, the notion that these factors can correctly organize a society and that they signify deeper attributes, which are indelible - this is the new idea at the heart of these new people who have been brought up hopelessly, tragically, deceitfully, to believe that they are white.... The new people were something else before they were white—Catholic, Corsican, Welsh, Mennonite, Jewish. ... As for now, it must be said that the process of washing the disparate tribes white, the elevation of the belief in being white, was not achieved through wine tastings and ice cream socials, but rather through the pillaging of life, liberty, labor, and land; through the flaying of backs; the chaining of limbs; the strangling of dissidents; the destruction of families; the rape of mothers; the sale of children; and various other acts meant, first and foremost, to deny [Coates and his young son] the right to secure and govern our own bodies. (pp. 6-7)

The powerful imagery behind "white" and the condition of whiteness carry unearned privilege, yet the power behind the label "white" is sustained because it goes unchallenged (Applebaum, 2003). I employ theoretical concepts drawn from Critical Whiteness Studies (CWS) to use as my theoretical frame because this branch of social theory was created to challenge and interrupt whiteness in order "to take seriously the complex nature of such privilege and how such privilege creates and sustains systems of oppression" (p. 9).

Leonardo (2007) argues whiteness operates invisibly so as to seem "innocent or harmless" (p. 79). Whiteness is the ubiquitous, unseen norms entrenched in the everyday that privilege whites and alienate people of color (Tranby \& Hartmann, 2008). Whiteness studies gives one the theoretical tools to reveal and challenge dominant narratives and can be used to 
make strange what seems "normal" or "the natural order of things." When I push against whiteness in this study, I do so in an effort to create alternative meanings that can be used to rise up and challenge the status quo (Semali, 2000).

In the context of schooling, whiteness manifests within the norms and traditions of educational institutions. When students of color do not see other students of color in certain classes, a norm of exclusion forms and becomes standard practice. The more excluded underrepresented students become, the more inequitable systems strengthen and the cycle perpetuates. Frankenberg (1993) contends whiteness is "maintained over time by a set of exclusionary practices" (p. 12). This is critically important to understand because these exclusionary practices do not seem exclusionary because they have been in place so long they become culturally situated as the standard, the norm.

Applebaum (2003) asserts the branch of social theory, Critical Whiteness Studies (CWS), came about as social theorists attempted to reveal invisible structures that bestow privilege on people who, as Coates (2015) theorizes, "believe themselves to be white.” Applebaum (2003) contends the danger in doing work that does not challenge unseen privilege is that "reputational privilege is seen as individual merit implying that those who do not obtain such privilege do not deserve such respect and dignity" (p. 14). Using CWS as my theoretical frame serves as one way to uncover and consider power structures, agency, and dominant norms used to marginalize students of color and re-center whiteness. Framing and re-analyzing a phenomenon using concepts from critical social theory allows the status quo to be questioned and creates space within which people relegated dominant-culture outsiders might be recognized (Rodriquez, 2000). Theorists of CWS caution all discourse is not meant naturally to focus on white people; the fact that dominant discourses focus on white people and are situated in whiteness further 
perpetuates whites' normative status. Theorists challenge the structural forces that perpetuate whiteness and the privileges it bestows on those in positions of power (Gillborn, 2005).

To go against prevailing norms and thoughts about CTE and its ability to be a driver of the U.S.' economic engine and consider alternative lines of inquiry takes deliberate, critical thought and CWS offers a frame that provides a means to examine CTE enrollment patterns that may reify whiteness while essentializing and oppressing students of color. I utilize CWS' (Applebaum, 2003) theoretical concepts of whiteness as property (Harris, 1993; McLaren, 2000; Semali, 2000; Tranby \& Hartmann, 2008), meritocracy (Mijs, 2016), colorblindness (BonillaSilva, 2005; Thompson, 1998), and individualism (Bryerton, 2016; DiAngelo, 2010) critically to re-analyze the descriptive statistics my quantitative analysis yields.

\section{Whiteness as Property}

A concept within Critical Whiteness Studies, whiteness as property invests individuals of the dominant group with a self-serving interest in maintaining the status quo. Harris (1993) theorizes whiteness as property functions as a tool to bestow social benefits - which can include physical property or anything else to which a person may assign value like a degree or certificate—on those who possess it. Whiteness as property allows those reaping whiteness' benefits to exclude others from receiving its benefits. Inequality is upheld because those who are ineligible or unable to receive whiteness' benefits cannot wield the same level of influence and power over resources, so the status quo is retained (Annamma, 2015). Those in power have a vested interest in maintaining property and influence, so their associated privileges stay concentrated within their group.

Annamma (2015) illustrates how something intangible, like innocence, can come to be seen as property and be maintained by the group entitled to claim whiteness as property. Those 
who "are without the protection of innocence are subject [to] suspicion, surveillance, and incarceration" (p. 298). In this instance and in the context of schooling, students who can claim whiteness as property benefit from a presumed innocence. Their actions are likely to be viewed as normal because whiteness operates as a cultural and sociopolitical baseline. Those who cannot claim whiteness as property are looked upon as "other," as different from the norm, so their actions may justifiably be called into question. Using this concept allows me critically to examine, as evidenced in the data, career pathways that provide benefits to white students while excluding students of color.

\section{Meritocracy}

The meritocratic character of The American Dream - the idea anyone can rise to prominence no matter how humble one's beginning - is deeply engrained in the psyche of the U.S. citizenry. Rags-to-riches stories capture the national imagination and indicate nothing is out of reach if one only works hard for it. Mijs (2016) contends meritocracy is a concept in which achievement appears to be and is maintained as "a function of [one's] natural ability and effort" (p. 16). Bowles and Gintis (2011) posit meritocracy helps "perpetuate the concept of social rank in a society increasingly eschewing distinctions of birth" (p. 98). In other words, to whom and where one is born have little to do with one's life outcome. All are mythologized to have equal opportunity for success. What matters is one's own ability to do well in school and work hard.

Bowles and Gintis (2011) assert "the educational system fosters and reinforces the belief that economic success depends essentially on the possession of technical and cognitive skills" (p. 103). In a meritocracy, one who cannot elevate his standing does so not by virtue of race or parental income but because he lacks merits. Lacking a certain credential, degree, or requisite work history are likely culprits that prevent mobility in a meritocracy. Bowles and Gintis (2011) 
argue schools are not meritocratic institutions where curriculum content is the priority. Rather, schools exist to reproduce the dominant social order so students can fit easily into the economic role in which they are expected and needed. Schools exist to serve the economy by introducing students to social relationships of the workplace. Depending upon the types of positions needed in the marketplace, students may find themselves in courses which can position them for supervisory roles or more subordinate roles. As a result, schools reproduce the inequitable division of labor found in the workplace (Bowles \& Gintis, 2011). As divisions become more acute, future implications arise. Students who attend school to learn blue-collar skills are unlikely to cross over to white-collar work, largely because upward social-class mobility is rare, yet The American Dream's prevalence doggedly persists in foregrounding and keeping alive the belief tremendous economic success can happen to anyone through hard work and grit (this idea also tightly tied to one's deservedness and goodness).

In a meritocracy, irrespective of one's societal standing, a person's merits determine one's fate. When an individual fails to achieve because of systemic oppression, in a meritocracy failure is assumed to rest with the individual rather than the system (Valencia, 2010), a deficitbased perspective that, in educational settings, blames students for their failures rather than the system which, by design, fails them. Markovits (2019) astutely argues bifurcation in the workforce is creating a system where the people in more prestigious occupations want to hold onto what they "earn" to be able to pass on their privilege to their children. Thus, meritocracy becomes a mechanism for passing along spoils instead of leveling the playing field. 


\section{Colorblindness}

Meritocracy is a powerful concept because, no matter a person's station in life, hard work and diligence are believed to be all that are needed to succeed, so race becomes moot (Giroux, 2019). The danger in white people adopting a colorblind attitude is "by suppressing colortalkthe explicit recognition that someone is [w]hite, Black, or Brown-[one] chooses to avoid rather than identify the racism that treats Blackness and Brownness as unmentionable" (Thompson, 1998, p. 524). Not noticing color completely dismisses the lived experiences of people of color and implies race and racism can simply go away if ignored (Thompson, 1998). Colorblindness seems like an egalitarian way of viewing individuals but individuals who claim colorblindness "[ignore] the structures of race, class, and gender relations that together posit color as a deficit in the first place" (Thompson, 1998, p. 525). By "not seeing" color, which in itself is a willed "not seeing," a refusal of race and its terrible U.S. history, people of color are effectively detached from their lived experiences, devoid of the rich cultural traditions which shape the way they view the world (Chapman, 2013). Reason and Evans (2007) submit colorblindness is alleged to create a level societal playing field once race disappears. Any inequities, be they against an individual or group of individuals, made manifest in a colorblind society are therefore a perversity of the individual or group. Colorblindness signifies race and racism are not salient concerns, diminishes institutional culpability in propping up unjust systems, and feeds meritocratic notions (Leonardo, 2007). To be colorblind is to live as though structural inequities do not exist for people of color. Semali (2000) asserts colorblindness puts a focus on the individual and serves to "legitimize the superiority of one race over another" (p. 181). Thompson (1998) contends educators who "fail to acknowledge and address the [w]hiteness of their political and cultural assumptions....are in effect colorblind" (p. 525). Examining CTE data must be done from a color-conscious 
perspective in order to account fully the experiences of students of color. When those experiences are on the same level as those of white students, then equitable structures in teaching and academic advising have a chance to flourish.

\section{Individualism}

Another theoretical concept, one that works in conjunction with meritocracy and colorblindness in ensuring race is rendered meaningless, is individualism. Individualism is centered in an individual's autonomy. In an individualistic worldview, recognition of how institutional and systemic barriers play a part in affecting one's life are not of concern (Bryerton, 2016; DiAngelo, 2010). I choose to use this concept in my re-analysis of descriptive statistics to draw attention to the ease with which largely white career pathways can seem normal and so go unquestioned. In individualism, an individual operates independently from one's family, heritage or neighborhood. Individuals exist independent of greater forces, have autonomy, and are individually accountable for their actions; this is an anti-collectivist worldview, a competitive worldview, and inconsistent with the ways of knowing and being of people of color invested in a collectivist cosmology. Individualism works in tandem with colorblindness because race is of no import. Individualism operates under the assumption that every individual has equal opportunity irrespective of race (DiAngelo, 2010). Tranby and Hartmann (2008) submit rugged individualism, the kind where settlers set about to tame the western frontier, is part and parcel of "American" culture, but it is based on "the Anglo-American culture as the normative cultural status" (p. 347). Because white lived experience operates as the center, the norm, the default, any theory that upholds whiteness' dominance must be dismantled so an honest effort can be made to make meaningful changes to social systems that address systematic, systemic oppression. 


\section{CHAPTER IV: DATA ANALYSIS}

\section{Introduction}

In this chapter I report my data analysis by first providing a summary of descriptive statistics of Illinois public high school CTE enrollments and overall demographic descriptive statistics to provide a top-level view of the state of Illinois public school enrollment along with the Illinois public high school CTE enrollment. After reporting descriptive analysis, I re-analyze my descriptive analysis using critical social theory in order to reveal alternative ways in which to consider CTE enrollment patterns, their meanings, and consequences. These alternative ways of interpreting my study's statistical outcomes connect to my commitment, as an interpretivist, to the social justice aspects and concerns descriptive analysis raises when viewed through my theoretical frame.

\section{Descriptive Statistical Analysis}

To begin the analysis, I turn to my first research question: Who enrolls in CTE courses in Illinois public high schools? While descriptive statistics do not allow me to intuit or comment upon the motivations and perspectives of students who enroll in CTE courses, descriptive statistics allow me to report accurately who enrolls and to identify patterns of social importance. Loeb et al. (2017) theorize descriptive statistics contain useful tools to uncover patterns in the data that "can serve as the foundation for...pointing toward causal understanding" (p. 27). In the following sections, I first report and examine who enrolls in CTE as borne out by the data. After reporting my descriptive analyses, I then go on to offer re-analysis of my descriptive analyses using a critical theoretical lens. My re-analysis, I submit, may help CTE teachers, administrators, and academic advisors to build a better understanding of Illinois' CTE system and assist them as they develop intervention strategies for building equity in CTE classrooms. 


\section{State Demographics}

Illinois' public high school CTE enrollment data do not exist in isolation. Students in CTE make up a portion of the over two million students who attend Illinois public schools. I first provide demographic information for all Illinois public school students to provide context for CTE enrollments. By providing a high-level picture of characteristics of Illinois public school students who do and do not enroll in CTE, patterns noted in CTE enrollment alone then have a point of reference. Table 1 displays ISBE (2016a) data on demographics by race during the 2015-2016 academic year:

Demographics by Race

Table 1: 2015-2016 Illinois Total Public School Enrollment by Race

\begin{tabular}{llc}
\hline Race & Frequency & Percent \\
\hline American Indian & 8,342 & 0.4 \\
Asian & 97,950 & 4.9 \\
Black & 339,613 & 17.0 \\
Hispanic & 516,210 & 25.8 \\
Pacific Islander & 2,112 & 0.1 \\
Two or more races & 67,879 & 3.4 \\
White & 970,727 & 48.5 \\
Total & $2,002,833$ & 100.0 \\
\hline
\end{tabular}

Data source: ISBE College and Career Readiness Division

ISBE data uses the term "Hispanic" as a racial designation. When not referring to table data in my analysis, I utilize the current, gender-neutral alternative, Latinx.

Table 1 data show students who identify as white constitute nearly half of all Illinois public school students, $48.5 \%$. The next two largest groups, students who identify as Hispanic 
and Black, make up $42.8 \%$ of all students: $25.8 \%$ and $17.0 \%$ respectively. Put another way, over $90 \%$ of Illinois students report they belong to one of three racial groups: white, Black, or Hispanic. This data is useful because it provides a type of baseline from which to consider CTE enrollment and whether they contain similar demographics.

\section{Illinois CTE Public High School Enrollment Demographics}

Total Illinois CTE enrollment during the 2015-2016 school year was 280,755 students, including duplicated headcount. Put another way, the data does not record the frequency an individual student enrolls in CTE courses. Although I do not make any claim to generalizability, I do wish to offer robust amounts of data on which to make claims and report findings. An $n$ of 280,755 represents a rich quantity of data. However, because the data included duplicated headcount, the actual $n$ is likely to be less. Additionally, the number of students enrolled in CTE courses constitutes $14 \%$ of all Illinois public school students and, I submit, makes closer inspection of CTE enrollments warranted. Table 2 reports the number of CTE enrollments classified by race. CTE enrollment demographics are markedly different than the overall racial makeup of Illinois' public schools. Students who identify as white outnumber all other racial groups by a large proportion and total over 169,000 students. For example, students who identify as white represent over three times the number of students who identify as Hispanic. 
Table 2: 2015-2016 Total Illinois Public High School CTE Enrollment by Race

\begin{tabular}{llc}
\hline Race & Frequency & Percent \\
\hline American Indian & 751 & 0.3 \\
Asian & 11,115 & 4.0 \\
Black & 38,488 & 13.7 \\
Hispanic & 53,032 & 18.9 \\
Pacific Islander & 7,764 & 0.1 \\
Two or more races & 225 & 2.8 \\
White & 169,379 & 60.3 \\
Total & 280,755 & 100.0 \\
\hline
\end{tabular}

Data source: ISBE College and Career Readiness Division

Students who identify as white make up over $60 \%$ of CTE enrollment, while those who identify as Black and Latinx comprise $32.6 \%$ percent of CTE students, although together they represent almost $43 \%$ of all Illinois public school students. Racially descriptive statistics indicate students of color are not represented to the same degree in CTE courses as they are in overall Illinois public school enrollment. The substantial overrepresentation of students who identify as white in CTE is worth noting considering they represent only $48.8 \%$ of all Illinois public school students, grades $\mathrm{K}-12$.

\section{Demographics by Gender}

Of the $60.3 \%$ total students who identify as white enrolled in CTE, 73,648 or $26.2 \%$ identify as female and 95,731 or $34.1 \%$ identify as male. As with race-based demographics, providing a picture of the entire state's demographics puts CTE enrollment related to gender into context. Table 3 shows gender demographics for all Illinois public school students. 
Table 3: 2015-2016 Total Illinois Public High School Enrollment by Gender

\begin{tabular}{llc}
\hline Gender & Frequency & Percent \\
\hline Female & 975,173 & 48.7 \\
Male & $1,027,660$ & 51.3 \\
Total & $2,002,833$ & 100.0 \\
\hline
\end{tabular}

Data source: ISBE College and Career Readiness Division

The gender makeup of students who identify as female or male in CTE courses changes relative to their overall representation in Illinois public schools, but enrollments do not shift as much as they do for race, $4.2 \%$ lower and $4.2 \%$ higher respectively. Table 4 reports percentages of males and females enrolled in Illinois' CTE courses.

Table 4: 2015-2016 Total Illinois Public High School CTE Enrollment by Gender

\begin{tabular}{llc}
\hline Gender & Frequency & Percent \\
\hline Female & 125,047 & 44.5 \\
Male & 155,707 & 55.5 \\
Total & 280,755 & 100.0 \\
\hline
\end{tabular}

Data source: ISBE College and Career Readiness Division

\section{Student Location Demographics}

Education for Employment (EFE) systems are state entities partly responsible for reporting CTE Perkins performance indicators to the federal government (ISBE, 2012). The data set includes EFE numbers which correspond to the EFE's location in the state. It is fitting to consider whether there is still an overrepresentation of students who identify as white in locales having a greater number of students of color, in particular in Chicago Public Schools (CPS). During the 2015-2016 school year, CPS (Chicago Public Schools, 2015) reports the following demographics: White 37,748 (9.6\%); African American 152,413 (38.9\%); Hispanic 180,206 
(45.9\%); and Asian 14,540 (3.7\%) (p. 1). In a school system in which students of color represent over $90 \%$ of the student body, CTE enrollment patterns showing an overrepresentation of white students seems unlikely. Table 5 which reports CTE enrollments for EFE 010, City of Chicago, indicate demographics similar to overall district demographics, not those of the state. By contrast, enrollment among students who identify as Black and Latinx are in line with overall district demographics evidencing students of color can constitute a majority of CTE students. Demographic information in Tables 6 and 7 illustrates the demographic breakdown of CPS' three most-enrolled CTE courses.

Table 5: 2015-2016 Chicago Public School CTE Enrollment

\begin{tabular}{llc}
\hline Race & Frequency & Percent \\
\hline Asian & 716 & 3.6 \\
Black & 9,420 & 47.6 \\
Hispanic & 7,883 & 40.0 \\
Other & 268 & 1.4 \\
White & 1,474 & 7.4 \\
Total & 19,761 & 100.0 \\
\hline
\end{tabular}

Data source: ISBE College and Career Readiness Division

Table 6: 2015-2016 Top Three Chicago Public School CTE Courses with Most Enrollment

\begin{tabular}{lc}
\hline Course Name & Percent \\
\hline Business and Technology Concepts & 24.3 \\
Communication Technology & 5.5 \\
Nutrition and Culinary Arts I & 4.7 \\
\hline
\end{tabular}

Data source: ISBE College and Career Readiness Division 
Table 7: 2015-2016 Top Three Chicago Public School CTE Enrollment as Percentages by Race

\begin{tabular}{lccc}
\hline Race & $\begin{array}{l}\text { Business and } \\
\text { Technology Concepts } \\
\text { Percent }\end{array}$ & $\begin{array}{l}\text { Communication } \\
\text { Technology } \\
\text { Percent }\end{array}$ & $\begin{array}{l}\text { Nutrition and } \\
\text { Culinary Arts I } \\
\text { Percent }\end{array}$ \\
\hline Asian & 4.5 & 5.8 & 0.6 \\
Black & 48.9 & 40.6 & 50.8 \\
Hispanic & 35.9 & 43.7 & 44.4 \\
Other & 1.3 & 2.6 & 0.8 \\
White & 9.4 & 7.3 & 3.4 \\
\hline
\end{tabular}

Data source: ISBE College and Career Readiness Division

CTE course enrollment largely maintains demographics similar to those of CPS' district demographics. The value in highlighting CTE enrollments where students of color are enrolled similarly to a district's demographic is this data provide a focal point for future researchers to investigate locations where equity in enrollments is already present. If students of color can constitute a majority status in CPS, then it logically should be possible for students of color to constitute a majority status in other locations where enrollment among students of color is high.

Table 8 contains CTE enrollment data for the Illinois region that includes Rockford Public Schools (RPS) in which the majority of students are students of color (Illinois State Board of Education, n.d.a). This location has the potential to enroll more students of color in CTE courses due to RPS having a high percentage of students of color. Unlike CPS, where students of color represent a majority of students enrolled in CTE, the location representing RPS students is not similar. Data show students of color represent only $42.7 \%$ of CTE students and presents another opportunity for university researchers to investigate CTE data based on location. 
Table 8: 2015-2016 EFE 150 CTE Enrollment

\begin{tabular}{llc}
\hline Race & Frequency & Percent \\
\hline Asian & 251 & 2.3 \\
Black & 1,513 & 13.9 \\
Hispanic & 2,420 & 22.2 \\
Other & 466 & 4.3 \\
White & 6,231 & 57.3 \\
Total & 10,881 & 100.0 \\
\hline
\end{tabular}

Data source: ISBE College and Career Readiness Division

Enrollment Patterns of Students of Color Compared to White Students

I now turn to my second research question: How do patterns in enrollment in CTE courses differ for students of color and their white counterparts? Here, the use of descriptive analysis allows me to display enrollment patterns of social import: the patterns as they exist in the data. Table 9 reports CTE enrollment by state course titles and lists the top 13 most-enrolled CTE courses in Illinois public high schools. I choose these 13 courses because they provide a base for analysis constituting over half of all CTE enrollment in the state of Illinois. The 13 most-enrolled classes represent $50.2 \%$ of the entire high school CTE enrollment, or over 140,000 students. Table 10 lists the top 13 courses with percentage enrollment by race. 
Table 9: 2015-2016 Top Half Illinois Public High School CTE Enrollment

\begin{tabular}{llcc}
\hline Course Name & Frequency & Percent & \% Cumulative \\
\hline Nutrition and Culinary Arts I & 38,031 & 13.5 & 13.5 \\
Business and Technology Concepts & 17,211 & 6.1 & 19.7 \\
Computer Concepts \& Software Apps. & 13,710 & 4.9 & 24.6 \\
Child Development \& Parenting & 11,146 & 4 & 28.5 \\
Family Resource Mgmt. \& Planning & 8,872 & 3.2 & 31.7 \\
Nutrition \& Culinary Arts II & 7,873 & 2.8 & 34.5 \\
Introduction to Tech. \& Eng. & 7,797 & 2.8 & 37.3 \\
Keyboarding and Formatting & 7,599 & 2.7 & 40 \\
Introduction to the Agricultural Industry & 6,590 & 2.3 & 42.3 \\
Introduction to Engineering Design (PLTW) & 6,400 & 2.3 & 44.6 \\
Culinary Occupations I & 5,326 & 1.9 & 46.5 \\
Intro. to Family \& Consumer Sciences & 5,193 & 1.8 & 48.4 \\
Cooperative Education & 5,177 & 1.8 & 50.2 \\
\hline
\end{tabular}

Data source: ISBE College and Career Readiness Division 
Table 10: 2015-2016 Top 13 CTE Enrolled Classes with Race and Percent Race by Course

\begin{tabular}{lllllll}
\hline Course Name & Asian & Black & Hispanic & Other & White & Total \\
\hline Nutrition and Culinary & 1,259 & 5,797 & 7,183 & 1,334 & 22,458 & 38,031 \\
Arts I & $3.3 \%$ & $15.2 \%$ & $18.9 \%$ & $3.5 \%$ & $59.1 \%$ & $100 \%$ \\
Business and Technology & 868 & 3,872 & 3,365 & 517 & 8,589 & 17,211 \\
Concepts & $5.0 \%$ & $22.5 \%$ & $19.6 \%$ & $3.0 \%$ & $49.9 \%$ & $100 \%$ \\
Computer Concepts \& & 535 & 2,284 & 1,645 & 420 & 8,826 & 13,710 \\
Software Apps. & $3.9 \%$ & $16.6 \%$ & $12.0 \%$ & $3.1 \%$ & $64.4 \%$ & $100 \%$ \\
Child Development \& & 316 & 1,602 & 2,615 & 360 & 6,253 & 11,146 \\
Parenting & $2.8 \%$ & $14.4 \%$ & $23.5 \%$ & $3.2 \%$ & $56.1 \%$ & $100 \%$ \\
Family Resource Mngt. \& & 387 & 1,194 & 1,840 & 317 & 5,134 & 8,872 \\
Planning & $4.4 \%$ & $13.5 \%$ & $20.6 \%$ & $3.6 \%$ & $57.9 \%$ & $100 \%$ \\
Nutrition \& Culinary Arts & 357 & 861 & 1,534 & 279 & 4,842 & 7,873 \\
II & $4.5 \%$ & $11.0 \%$ & $19.5 \%$ & $3.5 \%$ & $61.5 \%$ & $100 \%$ \\
Introduction to Tech. \& & 203 & 1044 & 1455 & 243 & 4852 & 7797 \\
Eng. & $2.6 \%$ & $13.4 \%$ & $18.7 \%$ & $3.1 \%$ & $62.2 \%$ & $100 \%$ \\
Keyboarding and & 217 & 1,122 & 1,442 & 289 & 4,529 & 7,599 \\
Formatting & $2.9 \%$ & $14.8 \%$ & $19.0 \%$ & $3.7 \%$ & $59.6 \%$ & $100 \%$ \\
Introduction to the & 18 & 146 & 219 & 127 & 6,080 & 6,590 \\
Agricultural Industry & $0.3 \%$ & $2.2 \%$ & $3.3 \%$ & $1.9 \%$ & $92.3 \%$ & $100 \%$ \\
Introduction to & 711 & 537 & 1,256 & 243 & 3,653 & 6,400 \\
Engineering Design & $11.1 \%$ & $8.4 \%$ & $19.6 \%$ & $3.8 \%$ & $57.1 \%$ & $100 \%$ \\
(PLTW) & & & & & & \\
Culinary Occupations I & 79 & 1,313 & 1,548 & 126 & 226 & 5,326 \\
Intro. to Family \& & $1.5 \%$ & $24.6 \%$ & $29.1 \%$ & $2.4 \%$ & $42.4 \%$ & $100 \%$ \\
Consumer Sciences & 67 & 530 & 594 & 202 & 3,800 & 5,193 \\
Cooperative Education & $1.3 \%$ & $10.2 \%$ & $11.4 \%$ & $3.9 \%$ & $73.2 \%$ & $100 \%$ \\
& 120 & 964 & 1,164 & 163 & 2,766 & 5,177 \\
\hline & $2.3 \%$ & $18.6 \%$ & $22.5 \%$ & $3.2 \%$ & $53.4 \%$ & $100 \%$ \\
\hline
\end{tabular}

Data source: ISBE College and Career Readiness Division

The top half of all CTE enrollments shows Family and Consumer Science (FCS) courses leading all other curricular areas. FCS courses are part of career pathways linked to occupations 
in the hospitality and service industry (National Association of State Administrators of Family and Consumer Science, n.d.). The combined enrollment of Nutrition and Culinary Arts I, Child Development and Parenting, Family Resource Management and Planning, Nutrition and Culinary Arts II, Culinary Occupations I, and Introduction to Family and Consumer Science, total 76,441 or $27.2 \%$ of all CTE enrollments. Over one quarter of Illinois public high school students who enroll in a CTE course are enrolled in an FCS class and, of those, over $11 \%$ are students of color. Moreover, the titles, save for Nutrition and Culinary Arts II, imply introductory-level coursework. While it is fitting the bulk of enrollments in CTE are at the introductory level, with subsequent class enrollments lessening as coursework specificity increases, it is worth examining these top-enrolled courses to determine if students of color are disproportionately represented in courses that lead to service-sector industries.

Loeb et al. (2017) theorize descriptive statistics allow a researcher to characterize phenomena, but caution descriptions are not useful unless those descriptions signify "patterns that are socially meaningful" (p. 9). I posit patterns which display students of color's course enrollment leading to low-wage occupations is socially important. Additionally, courses representing the upper half of all CTE enrollments provide insight about the types of career pathways that begin in the Illinois public secondary system.

An engineering pathway that begins in Illinois public high schools is likely to include Introduction to Engineering Design, the tenth most-enrolled class during the 2015-2016 school year. These numbers appear to be compatible with Bureau of Labor Statistics (Torpey, 2015) projections that report most STEM-related job openings are in engineering. BLS estimates 100,000 mechanical engineers will be needed by 2022 and can earn over $\$ 100,000$ a year. Given 
the earning potential for a student who follows that career pathway and secures an engineering job, for example, Illinois engineering pathway demographics are important to consider.

Unique to the one course with "engineering" in the title is the number of students who identify as Asian. Overall, in Illinois public high schools' CTE courses students who identify as Asian account for $4.0 \%$ of enrollment. The percentage of representation does not differ when regarding top-13 CTE courses, save for enrollment in Introduction to Engineering Design. Enrollment for students who identify as Asian increases to $11.1 \%$ in Introduction to Engineering Design, more than double any other class in which Asian students enroll. Students who identify as Latinx and white represent $19.6 \%$ and $57.1 \%$ respectively. Their representation in Introduction to Engineering Design is akin to their overall representation in CTE courses. Students who identify as Black make up $8.4 \%$ of enrollment in Introduction to Engineering Design, far less than the nearly $14 \%$ representation they have across all CTE courses.

Introduction to Engineering contains an additional descriptor in the title: PLTW, which stands for Project Lead the Way (n.d.). PLTW is a program dedicated to "inspiring, engaging, and empowering $\mathrm{K}-12$ students” ( $₫ 1$ ). Indeed, "PLTW provides activity-, project-, problembased curricula and teacher professional development. After adopting a PLTW program, teachers are trained [by an approved state provider] in PLTW courses and receive access to course curricula" ( (52). A fee of up to $\$ 5,000$ per school is assessed to use the supplied curriculum.

Descriptive analysis cannot answer why Asian students are enrolled in a course but can identify a socially important aspect of the phenomenon. Increased enrollment by students who identify as Asian, as evidenced in the data, is a phenomenon that might not have been made visible had only causal relations been examined. Students who identify as Black comprise only 
$8.4 \%$ of PLTW's introductory class even though they make up nearly $14 \%$ of total CTE enrollment.

\section{Analysis Using Logistic Regression}

I have argued descriptive analyses of Illinois CTE career pathways make a contribution to the field by exposing patterns in data which can assist CTE practitioners in identifying not only who enrolls in CTE courses, but also future content areas to study. I next add another level of meaning to answer my third research question: Given patterns in course-taking, to what extent do students of color enroll in classes leading to STEM career pathways? My aim in posing this question is to take patterns presented in the data and point toward a more causal understanding of the relationship between students of color and STEM career pathways.

Because descriptive analysis of an archival database amounts to a type of autopsy, meaning no intervention took place and I can only offer what was already present in the data set, my last analysis represents an effort to determine the likelihood students of color will enter into lower-wage or less-prestigious career pathways. With this work I aim to provide direction for future researchers in CTE on topics like STEM and how students of color come to enroll in such courses.

Binary logistic regression is a useful tool when considering the likelihood of students of color entering into STEM career pathways. Using a categorical dependent variable with a yes or no outcome, enrolled in STEM class or not enrolled in a STEM class, statistical software, when independent variables are added, can calculate the odds or probability of an event occurring. For example, a medical patient might find an odds ratio about a speedy recovery useful. In this scenario a speedy recovery is the dependent variable because a patient either has a speedy recovery or does not have a speedy recovery: yes or no. A patient's gender added to the model 
works as the independent variable. In this example, an odds ratio of 2.0 for female signifies the odds of a female having a speedy recovery is twice as large as a male (Vogt, 2007). In my study, logistic regression provides information about the odds of students enrolling in STEM career pathways based on their race, gender, and free-and-reduced-lunch status.

Like the medical example on the odds of a speedy recovery, I employ one dependent and one independent variable. STEM is the dependent variable and gender is the independent variable. When using binary logistic regression, the underlying assumption is there is no relationship between the independent and dependent variables. For this study and this first model of a binary logistic regression, the assumption or null hypothesis is there is no relationship between gender and being enrolled in a STEM-related career pathway. If the assumption of no relationship bears out, SPSS will show an odds ratio of one. An odds ratio above one indicates odds are increasing and less than one indicates decreasing odds. Table 9 reports SPSS output for a binary logistic regression with STEM as the dependent variable and gender as the independent variable; the odds ratio is found in column $\operatorname{Exp}(\mathrm{B})$. In the first model, the odds ratio is 3.038; that is to say Illinois public high school males are three times more likely to be enrolled in a STEM career pathway than females. The significance level, displayed in the Sig. column, is .000. This statistical significance level provides confidence for me to reject any assumption gender has no relationship with enrollment in a STEM career pathway. There is a relationship and, as evidenced in by the data, females are less likely to be enrolled in STEM classes than their male peers. Adding more independent variables when using a binary logistic regression offers the researcher the ability to control for other factors; the next model displays how gender and race affect enrollment in a STEM course. 
Table 11: Binary Logistic Regression: STEM and Gender

\begin{tabular}{lccllcr}
\hline Variable & B & S.E. & Wald & Df & Sig. & Exp(B) \\
\hline Gender & 1.111 & .008 & 19655.757 & 1 & .000 & 3.038 \\
Constant & -.644 & .006 & 11615.244 & 1 & .000 & .525 \\
\hline
\end{tabular}

Variable(s) entered on step 1: Gender

Data source: ISBE College and Career Readiness Division

In my second model, the logistic regression uses the dependent variable STEM and the independent variables race, gender, and free-and-reduced lunch. Free-and-reduced lunch is a proxy for students who come from a lower SES and are likely to be students of color. Like the first model, the assumption is race, free-and-reduced-lunch status, and gender have no relationship to whether an Illinois high school student is enrolled in a STEM career pathway. Table 12: Logistic Regression for STEM CTE Enrollment

\begin{tabular}{lrrrrrrr}
\hline Variables in Equation & B & \multicolumn{1}{c}{ S.E. } & \multicolumn{1}{c}{ Wald } & Sig. & $\operatorname{Exp}(\mathrm{B})$ & $95 \%$ & CI for $\operatorname{Exp}(\mathrm{B})$ \\
\hline Black & -.168 & .013 & 181.223 & .000 & .845 & .824 & .866 \\
Latinx & -.172 & .011 & 248.299 & .000 & .842 & .824 & .860 \\
Asian & .188 & .020 & 83.832 & 1.000 & 1.206 & 1.159 & 1.256 \\
Other & -.184 & .023 & 64.127 & 1.000 & .832 & .796 & .871 \\
Female & -1.112 & .008 & 19609.395 & .000 & .329 & .324 & .334 \\
FRL & -.107 & .009 & 149.644 & .000 & .898 & .883 & .914 \\
Constant & .585 & .009 & 4249.005 & .000 & 1.795 & & \\
\hline
\end{tabular}

Variable(s) entered on step 1: Race, Gender, FRL

Data source: ISBE College and Career Readiness Division

The odds ratio or likelihood of a student being enrolled in STEM is found in column $\operatorname{Exp(B).~Any~value~less~than~one~indicates~the~odds~or~likelihood~of~being~enrolled~in~a~STEM~}$ 
career pathway decreases while a value of more than one indicates the odds of being enrolled in a STEM career pathway increases.

CTE students who identify as Black, Latinx, other race, female, or free-and-reducedlunch status have odds ratios of less than one, meaning their chances of being enrolled in a STEM career pathway decrease. Put another way, students of color, save for Asian and white students, are $15 \%$ less likely to be enrolled in a STEM-related career pathway course. Moreover, the model shows a statistical significance associated with the odds ratios so I may rule out the assumption that race, gender, or SES have no relationship to being enrolled in a STEM pathway. By rejecting the assumption there is no relationship between a student's enrollment in a STEM course I consider alternative explanations in my re-analysis.

\section{Asian Students More Likely to Be Enrolled in STEM Courses}

Despite making up only four percent of total CTE students, CTE students who report identifying as Asian are $20 \%$ more likely to be enrolled in a STEM career pathway. That is to say Asian students, a group that represents less than a third of Black students' CTE enrollment have better odds of being enrolled in a course leading to a STEM-based, prestigious career pathway. One reason for this may be school counselors and instructors subscribe to a model minority stereotype, disproportionately enrolling Asian students into STEM-related courses (Lee, 2005). Analysis should not focus only on students of color and why they seem to enroll less in STEM. Rather, turning the analysis around and asking why Asian and white students have increased odds of being enrolled in STEM courses is a better question for CTE educators and policymakers to consider how whiteness plays a role in CTE. 


\section{CTE Enrollments with Parity}

CTE enrollments where data show more parity between groups are also worth noting. Deeper looks into courses displaying racial and gender parity might provide researchers insight into why a more diverse student make up is evident. Data show an occupational area where parity exists, as a percentage of total enrollment, is healthcare-related courses. Students of color represent $52.5 \%$ and $45.7 \%$ of total enrollment in Orientation to Health Occupations and Nursing Assistant respectively as shown in Table 11 .

Table 13: 2015-2016 Illinois Public High School Health Occupations Enrollment by Race and Percent of Course

\begin{tabular}{lllllll}
\hline Course Name & Asian & Black & Hispanic & Other & White & Total \\
\hline $\begin{array}{l}\text { Orientation to } \\
\text { Health }\end{array}$ & 313 & 733 & 782 & 113 & 1,755 & 3,696 \\
Occupations & $8.5 \%$ & $19.8 \%$ & $21.2 \%$ & $3.1 \%$ & $47.5 \%$ & $100 \%$ \\
Nursing & 123 & 292 & 557 & 60 & 1,224 & 2,256 \\
Assistant & $5.5 \%$ & $12.9 \%$ & $24.7 \%$ & $2.7 \%$ & $54.3 \%$ & $100.0 \%$ \\
\hline
\end{tabular}

Data source: ISBE College and Career Readiness Division

Courses represented in Table 13 are notable because BLS (Torpey, 2015) data project healthcare-related jobs to have the most openings now and up to 2022, which may bode well for future students. Considering some CTE courses are made up of $90 \%$ white students, courses with high representation of students of color are worth examining and considering why they enroll a more diverse student body than other courses.

\section{Majority of CTE Courses Are Introductory in Scope}

Data also show over $50 \%$ of CTE course enrollments are at the introductory level, as noted by course titles with "introduction" or "level one" in the name. Remaining CTE courses run a gamut of topics offering an array of choices including "II" in the title, indicating a subject- 
matter continuation at a more complex or higher level. Examining CTE course titles, it does not appear business and industry links to courses are readily present. Data did not yield courses with proprietary names of industry or software, like Microsoft or Adobe. Additionally, data did not contain information about any type of industry-related credential a student might obtain as a result of a course. Any specific links a course or curriculum has to business and industry would need to be investigated at the school level and outside the scope of this study. It is important to watch developments in credentialing because CTE enrollments show white students, who outnumber students of color, are more likely to reap benefits that might result from obtaining a credential.

\section{Reanalysis of the Descriptive Analysis}

In my re-analysis of the descriptive analysis, I raise three claims: 1) Enrollment differences across race between Illinois' STEM-related and Family and Consumer Sciences (FCS) courses and career pathways suggest the U.S.' large-scale, cultural, race-based limits of meritocracy extend to CTE pathways; 2) Illinois' disproportionately high enrollment levels among students of color in entry-level Family and Consumer Sciences courses reveal stark racial differences in CTE enrollment pathways to low-paying food-service jobs; and, 3) enrollment in Illinois' agricultural classes indicates a notable exclusion of students of color.

\section{Enrollment Differences Between STEM-Related and Family \& Consumer Science Courses}

Enrollment differences across race between Illinois' STEM-related and Family and Consumer Sciences courses and career pathways suggest the U.S.' large-scale, cultural, racebased limits of meritocracy extend to CTE pathways. Data show students who identify as white as more likely to be enrolled in STEM-related career pathways. Data in Table 14 show a clear 
white majority in STEM-related courses. Courses in STEM align with BLS occupational definition of STEM.

Table 14: 2015-2016 Illinois Public High School STEM Enrollment by Race and Percent of Course

\begin{tabular}{lllllll}
\hline Pathway & Asian & Black & Hispanic & Other & White & Total \\
\hline \multirow{2}{*}{ STEM } & 6,061 & 17,795 & 25,023 & 4,037 & 85,469 & 138,386 \\
& $4.4 \%$ & $12.9 \%$ & $18.0 \%$ & $3.0 \%$ & $61.7 \%$ & $100 \%$ \\
\hline
\end{tabular}

Data source: ISBE College and Career Readiness Division

According to Bureau of Labor Statistics (Torpey, 2015), STEM-related occupations typically yield higher wages for workers. Exclusion of students of color at an entry point for a STEM-related career pathway has the potential to set up future impediments for students of color. Perkins legislation stipulates CTE courses should be non-duplicative, progressive, and lead to some type of credential (U.S. Congress, 2006). Because STEM-related credentials are directly tied to high-wage potential, any credential or benefit available to white students as a result of enrolling in a STEM course can be regarded as a type of property. Because whiteness is normalized, any advantages that befall white students who in enroll in STEM courses often appears justified and normal (Harris, 1993). Students of color who cannot take advantage of a well-implemented STEM pathway will therefore be at an economic and social disadvantage relative to their white peers. The way in which course content builds from course to course and having the ability to earn early-career credentials will not be available to students of color. This inequity poses a danger to students of color because, in a meritocratic society, lacking a prestigious STEM background or credential can be assumed to be due to students of color's unwillingness to enroll in challenging courses or to inherent intellectual shortcomings like assuming students of color lack needed skills to be successful in STEM-related fields of study. 
Table 15 shows the combined enrollment of two courses: Nutrition and Culinary Arts I \& II. Enrollment in these two courses closely mirrors overall CTE demographics, which is to say the representative racial make-up of students is about the same across all CTE courses. However, for students who identified as Black, enrollment in these two courses results in $17 \%$ of the courses' total enrollment. Put another way, of the over 38,000 students who identify as Black and enroll in a CTE course in Illinois, nearly one in five enrolls in Nutrition and Culinary Arts I or II. As evidenced by the data, students of color are less likely to be in STEM-related courses, except for students who identify as Asian. One element of meritocracy is "educational opportunity [being] matched to natural ability" (Mijs, 2016, p. 16). Therefore, the overrepresentation of students who identify as white in STEM-related courses, based on a meritocratic educational system, must be due to white students' natural ability, not to their race-based privilege. In this example, "meritocracy provides a principle of justice for the allocation of reward: Whoever performs best justly deserves the highest reward" (Mijs, 2016, p. 17). Moreover, since such rewards can be shown to be just, the actions that lead to these rewards are also likely to be ensconced in colorblind attitudes. Without employing race as a deciding factor and employing the assumption of neutrality which stems from meritocratic tenets, differences in enrollments between STEM-related courses and FCS courses might be assumed to be natural occurrences, and therefore go unexamined. By re-analyzing my descriptive analysis, race-based differences and the attitudes that underlie them become more pronounced. While no causal relationships can be explained by my descriptive analysis, important phenomena nevertheless are made apparent and a potential focal point for CTE teachers, administrators, and advisors emerges. 
Table 15: 2015-2016 Illinois Public High School Nutrition and Culinary Arts I \& II Enrollment by Race and Percent of Course

\begin{tabular}{lllllll}
\hline Pathway & Asian & Black & Hispanic & Other & White & Total \\
\hline Nutrition \& & 1,616 & 6,658 & 8,717 & 1,613 & 27,300 & 45,904 \\
Culinary Arts & $3.5 \%$ & $14.5 \%$ & $19.0 \%$ & $3.5 \%$ & $59.5 \%$ & $100 \%$ \\
I \& II & & & & & & \\
\hline
\end{tabular}

Data source: ISBE College and Career Readiness Division

\section{Majority of Students of Color Enrolled in Service-Sector Pathways}

Illinois' disproportionately high enrollment levels among students of color in entry-level Family and Consumer Sciences courses reveals stark racial difference among CTE enrollment pathways to food-service jobs and this revelation calls into question how students of color in particular enter such pathways, warranting inquiry into CTE's institutional processes related to institutional mission and advising, among other processes.

Processes related to how students enroll in courses may differ from high school to high school, but at least two components to course selection share a common thread in Illinois: 1) students are required to register for courses mandated by the state of Illinois; and, 2) courses outside of state requirements may include electives like CTE courses (ISBE, 2016c). The ways in which students of color enroll in elective courses intersect with my theoretical concepts of whiteness as property, meritocracy, colorblindness, and individualism and expose inequitable enrollment patterns that marginalize students of color.

In Illinois, CTE's number-one-enrolled course with the largest number of students of color, Foods and Nutrition I, is important to examine not so much by where students of color reside but by where they remain unrepresented in ISBE data. Harris (1993) contends whiteness as property manifests as a continued right to exclude. As evidenced by ISBE data, students of color are not being excluded from Foods and Nutrition I. Rather, they appear to be excluded 
from STEM-related courses that have a potential to yield varied and dynamic career opportunities (Carnevale, Jayasundera, \& Hanson, 2012) since their representations in STEM courses appears strongly misaligned with population demographics and Illinois high school enrollment generally. By critiquing the enrollment pattern of Foods and Nutrition I, I certainly do not attempt to negate any beneficial aspects that result from students enrolling in the course but re-analysis of descriptive analysis employing theoretical concepts from whiteness studies enables the questioning of power dynamics at play in Illinois CTE enrollments (Delgado \& Stefancic, 2012).

In a meritocratic society, citizens are assumed able to better their societal standing by the merits of their works. The metaphorical economic playing field is therefore level and all persons, irrespective of race or gender, have equal opportunity to succeed, objectively rendering racial difference moot. In a meritocracy, rewards are given to those with the requisite talent and drive (Seron, Silbey, Cech, \& Rubineau, 2018). Rewards, in the form of being able to enroll in STEMrelated CTE courses, appear to be going primarily to those students who identify as white. Not questioning why students of color are more likely to be in service-related courses rather than STEM-related courses presumes meritocratic assumptions are at work beneath Illinois CTE enrollments. Justifying clear racial enrollment differences with a meritocratic argument "justifies the distribution of status and reward as just dessert for individual effort and accomplishment" (Seron et al., 2018, p. 137). However, since secondary courses provide a beginning to career pathways, it seems unlikely students who identify as white have amassed some level of professional acumen which warrants being rewarded. Rather, whiteness as property, as Harris (1993) posits, allows the status quo-in this case an overrepresentation of whites in STEMrelated courses - to be considered neutral, obscuring enrollment inequities in the exclusion of 
students of color. This obfuscation is then exacerbated by overlaying the Western narrative of individualism which focuses one's "free choice" on the individual's independence and personal autonomy rather than on inequitable, systemic forces of oppression (Wang, Castro, \& Cunningham, 2014). CTE advisors', policymakers', and instructors' focus on individual students, while perhaps seemingly aligned with best pedagogical practices, instead engineers and reinforces missed opportunity to question CTE's highly racialized status quo, evidenced by data that reveal students of color disproportionately enrolled in courses leading to low-skill occupations. This systemic inequity effectively removes students of color from the meritocratic educational enterprise, tracking them into subordinate pathways while students who identify as white are reliably tracked into career pathways of privilege.

\section{Agricultural Enrollments Show Exclusion of Most Students of Color}

The rugged individual seizing and taming a savage land and the manifestation of one's destiny is part of The American Dream trope's DNA. Industriousness and hard work are considered key ingredients of success and perhaps there is no better representation of these attributes than the individual farmer toiling in the fields (Andersen, 2017). As farming technologies have evolved, CTE maintains a connection to agriculture dating back to the Morrill Act (U.S. Congress, 1862). Although not named CTE at the time, funding for schools teaching mechanical arts was appropriated to assist with the ever-more-technical nature of agricultural production. Because of a long history linking the agricultural industry with CTE, and because

there are numerous Illinois CTE courses related to agriculture, I argue examining Illinois' high school agricultural courses' enrollments will likely expose inequities germane to this study. 
Table 16: 2015-2016 Illinois Public High School Agricultural Enrollment by Race and Percent of Course

\begin{tabular}{|c|c|c|c|c|c|c|}
\hline Course Name & Asian & Black & Hispanic & Other & White & Total \\
\hline \multirow{2}{*}{$\begin{array}{l}\text { Agricultural } \\
\text { Biotechnology }\end{array}$} & 3 & 2 & 3 & 0 & 51 & 59 \\
\hline & $5.1 \%$ & $3.4 \%$ & $5.1 \%$ & $0.0 \%$ & $86.4 \%$ & $100 \%$ \\
\hline \multirow{2}{*}{$\begin{array}{l}\text { Agricultural } \\
\text { Business } \\
\text { Management }\end{array}$} & 10 & 25 & 49 & 13 & 1,368 & 1,455 \\
\hline & $0.0 \%$ & $1.7 \%$ & $3.4 \%$ & $0.9 \%$ & $94.0 \%$ & $100.0 \%$ \\
\hline \multirow{2}{*}{$\begin{array}{l}\text { Agricultural } \\
\text { Communications }\end{array}$} & 3 & 100 & 35 & 11 & 192 & 341 \\
\hline & $0.09 \%$ & $29.3 \%$ & $10.3 \%$ & $3.2 \%$ & $56.3 \%$ & $100.0 \%$ \\
\hline \multirow{2}{*}{$\begin{array}{l}\text { Agricultural } \\
\text { Const. and Tech. }\end{array}$} & 0 & 4 & 16 & 8 & 425 & 453 \\
\hline & $0.0 \%$ & $0.9 \%$ & $3.5 \%$ & $1.8 \%$ & $93.8 \%$ & $100.0 \%$ \\
\hline \multirow{2}{*}{$\begin{array}{l}\text { Agricultural Co- } \\
\text { op }\end{array}$} & 0 & 0 & 1 & 1 & 16 & 18 \\
\hline & $0.0 \%$ & $0.0 \%$ & $5.6 \%$ & $5.6 \%$ & $88.9 \%$ & $100.0 \%$ \\
\hline \multirow{2}{*}{$\begin{array}{l}\text { Agricultural } \\
\text { Machinery } \\
\text { Service }\end{array}$} & 0 & 12 & 11 & 4 & 168 & 195 \\
\hline & $0.0 \%$ & $6.2 \%$ & $5.6 \%$ & $2.1 \%$ & $86.2 \%$ & $100.0 \%$ \\
\hline \multirow{2}{*}{$\begin{array}{l}\text { Agricultural } \\
\text { Mechanics \& } \\
\text { Tech. }\end{array}$} & 0 & 34 & 27 & 20 & 989 & 341 \\
\hline & $0.0 \%$ & $3.2 \%$ & $2.5 \%$ & $1.9 \%$ & $92.4 \%$ & $100.0 \%$ \\
\hline \multirow{2}{*}{$\begin{array}{l}\text { Agricultural } \\
\text { Metal } \\
\text { Fabrication }\end{array}$} & 0 & 2 & 1 & 0 & 38 & 341 \\
\hline & $0.0 \%$ & $4.9 \%$ & $2.4 \%$ & $0.0 \%$ & $92.7 \%$ & $100.0 \%$ \\
\hline \multirow{2}{*}{$\begin{array}{l}\text { Agricultural } \\
\text { Sales \& } \\
\text { Marketing }\end{array}$} & 0 & 116 & 9 & 4 & 177 & 341 \\
\hline & $0.0 \%$ & $7.8 \%$ & $4.4 \%$ & $1.9 \%$ & $85.9 \%$ & $100.0 \%$ \\
\hline
\end{tabular}

Data source: ISBE College and Career Readiness Division

Table 16 reports nine CTE courses containing the word "agricultural" in the title. Among those courses, students who identify as white make up over $80 \%$ of enrollments save for one, Agricultural Communications. Agricultural Communications is the only course in which 
enrollment for students who identify as Black and Latinx exceeds $10 \%$ : $29.3 \%$ and $10.3 \%$, respectively. Students who identify as Asian represent $0.1 \%$ of all students taking these courses. While an overrepresentation of students who identify as white is not surprising given the demographics of Illinois CTE students or given the state's focus on the agricultural industry, four agricultural courses have enrollments of over $90 \%$ white students. I argue descriptive analysis of Illinois CTE courses containing "agricultural" in the title showcase how descriptive analysis has the potential to reveal "issues that warrant immediate attention" (Loeb et al., 2017, p. 3).

Illinois is a major producer of soybean and corn crops which helps Illinois' agricultural industry generate over $\$ 19$ billion annually (Illinois Department of Agriculture, 2019). Besides agriculture being important to the state's economy, it is also an important part of the state's educational system, evidenced by agricultural education having its own line-item in Illinois' budget (ISBE, 2019). With state monies specifically appropriated for helping fund agricultural education in Illinois high schools, I maintain the heavily white status quo of agricultural enrollments cannot be left unremarked upon.

Inspecting agricultural course enrollments using the theoretical concepts of individualism and meritocracy brings into question students' agency and their ability to act freely to enroll in classes they choose without extraordinary involvement from others. And, under meritocratic conditions, "statuses are earned and not inherited; unequal outcomes are thus traceable to unequal demonstrations of ability, effort, and ambition (Bryerton, 2016, p. 81). Under individualistic and meritocratic conditions, the lack of students of color in agricultural courses is assumed to be a byproduct of individual choice and ambition rather than attributable to systemic inequities (Bryerton, 2016; DiAngelo, 2010; Oyserman, 2006). 
Nine agricultural courses, in total, enroll 3,544 students. Relative to the 38,031 students enrolled in Nutrition and Culinary I, this number is small, but it displays a content area of Illinois public high schools that is highly segregated and nearly completely devoid students of color. While in my descriptive analysis or interpretivist re-analysis I cannot offer why this might be the case, I can document the large majority of students who enroll in Illinois high school agricultural classes identify as white. When students of color are excluded from certain CTE career pathways, certain occupations become "whitewashed," and benefits continue to be bestowed on the majority. Furthermore, largely white enrollment patterns are assumed to be naturally occurring and politically neutral, treated merely to occur as a result of autonomous student choice (Harris, 1993). Given Illinois agriculture's prominent economic position and given that agricultural education has its own state-budget line-item, stark lack of students of color enrolling in agricultural education means students of color are effectively excluded from making contributions within Illinois' agricultural career pathway. 


\section{CHAPTER V: FINDINGS, IMPLICATIONS, AND RECOMMENDATIONS}

In this chapter I present findings, implications, limitations, and recommendations. This descriptive study was designed to investigate Illinois public high schools' CTE enrollment patterns among students of color, how patterns among students of color differ than that of their white peers, and the likelihood students of color will enroll in courses leading to more prestigious, higher-wage career pathways such as STEM pathways. I set out to characterize the phenomenon of CTE enrollment patterns as well as shed light on data elements that expose inequities perhaps not previously recognized (Loeb et al., 2017).

While Illinois CTE, within which students of color are far less well-represented than are their white peers, may not operate as a tracking mechanism in the aggregate, students of color do appear relegated to courses that lead to more service-sectors careers. Based on this evidence, CTE educators may be practicing colorblind admissions and advising processes since courses in career pathways like agriculture are predominantly white and CTE enrollment demographics often are attributed to students' likes and dislikes and not systemic inequities. Lastly, I discuss my study's limitations and how those limitations might be overcome by future researchers.

\section{CTE as a Tracking Mechanism}

Given enrollment data showing white students constitute the majority of Illinois' CTE students, I conclude CTE is not a tracking mechanism for students of color in the aggregate. These data are similar to other researchers' findings; they report fewer students of color enroll in CTE than their white counterparts (Hamilton, Malin, \& Hackmann, 2015; Rojewski \& Xing, 2013). In order to evidence a claim of tracking, enrollment data would have to reflect a far higher proportion of students of color enrolled in CTE courses. Table 2 displays enrollments by race and the overrepresentation of white students in Illinois CTE courses is apparent. If students of 
color were being tracked into CTE en masse, I submit it would be evidenced by the data. Taking the total Asian, Black, and Hispanic CTE student numbers into account, enrollment amounts to $36.6 \%$ or 102,635 students, still far below that of white students' enrollment in CTE. When enrollment of the three largest ethnic subgroups trails white students enrolled in CTE by 66,744 students, it becomes clear CTE, in general, is either not being sought out by students of color or students of color are not advised into CTE courses. If, however, the U.S. remains at risk of losing its competitive edge in the marketplace, and if CTE is a means through which to maintain a position of economic prominence, a proportion of students of color in alignment with the state's demographics should be found among CTE course enrollment to ensure the U.S. is supported by a diverse workforce (Hamilton, Malin, \& Hackmann, 2015) and so remains competitive in the global economy.

\section{A Pipeline Devoid of Color}

CTE has a long, storied history in which policymakers and educators continue efforts to put in place seamless systems where secondary students may enroll in courses that begin a career pathway, receive additional training and education at a community college or university and, ultimately, enter the workforce in their chosen career pathway. If, as policymakers hope, students are to transition seamlessly from point to point along a pathway, CTE is troubling in that it is a pipeline with far too little racial diversity, with Chicago Public Schools being a notable exception. From the data, I am unable to determine if this is an issue of location or a factor of internal CPS mechanisms.

If students' career paths can be considered a proxy for future workforce demographics, then the future workforce will continue to be absent people of color much like Rockford, Illinois' nursing shortage story I offer. If, from the beginning, a career pathway fails to enroll a racially 
diverse student body, a white status quo will be maintained. I situate this study in research on the underrepresentation of students of color in CTE (Hamilton, Malin, \& Hackmann, 2015; Morrell \& Parker, 2015; Rojewski \& Xing, 2013). I choose to re-analyze data using critical social theory to reveal hidden meaning on potential educational inequities in CTE: structures designed to uphold the status quo. Researchers Bragg (2005) and Hamilton, Malin, and Hackmann (2015) purport that, if business bottom lines improve as a result of the CTE system, then the system yields a net positive. When focusing so heavily on CTE's contribution to the U.S.' economic bottom line, maintaining industry's competitive edge becomes far more pertinent than questioning why white students continue grossly to outnumber students of color in CTE courses. I intend my study to ensure a lack of students of color in CTE cannot simply be dismissed as a problem students of color bring on themselves. Rather, an inequitable system, one that reinforces white privilege, and those who have power in the system shift to become the causal foci.

\section{Focusing on Systemic Inequities Rather than STEM}

Recruitment-related efforts to enroll more students of color into pathways such as STEM — where recruitment is focused on students' likes and dislikes — overlooks inequities within CTE's system and structure and wastes resources aimed at trying to "fix" students of color, not address the overarching, oppressive system.

Students who identify as white comprise $48.5 \%$ of Illinois CTE enrollment, yet constitute $60 \%$ of total CTE enrollment. This disparity cannot be passed off as "just the way things are" or as naturally occurring, because to do so allows critique of CTE to be couched within colorblindness and the tropes of individualism and meritocracy, reinforcing and maintaining existing privilege among white student enrollees. 
While Asian students comprise only 4\% of Illinois' CTE student enrollment in high schools, in STEM-related career courses they compromise as much as $11 \%$ of total enrollment. This discrepancy is significant because Latinx and Black students make up a far higher percentage of Illinois' public high school enrollment, $25.8 \%$ and $17 \%$ respectively, but Latinx and Black CTE students fall below their Asian peers in STEM enrollments, and their absence in STEM career pathways cannot be overlooked if Illinois and the U.S. are to mount a diversified workforce. Hamilton, Malin, and Hackmann (2015) and Asunda, Kim, and Westberry (2015) confirm this disparity and posit more research is needed to ensure CTE course enrollments are more equitable, so the present study fits within the scope of these influential scholars' work.

\section{Service-Sector Jobs for Students of Color}

Illinois' CTE courses are largely introductory and largely service-sector orientated; 52\% of all CTE courses are introductory in level. The majority of enrolled students of color are found in these courses, determining which CTE students move toward service-sector jobs. Even if students in these courses were to receive some type of industry credential, it is likely to be of only superficial value and unlikely to provide the student with a particular edge over those who remain uncredentialed. Economic disparity across CTE students' earning potential will continue to widen if students of color are relegated to service-sector career pathways. STEM career pathways are seen as a path to upward social-class mobility, but data show students of color have decreased odds of entering STEM-focused career pathways.

\section{Limitations}

I employ Critical Whiteness Studies (Applebaum, 2003) and the theoretical concepts of whiteness as property (Harris, 1993; McLaren, 2000; Semali, 2000; Tranby \& Hartmann, 2008), meritocracy (Mijs, 2016), colorblindness (Bonilla-Silva, 2005; Thompson, 1998), and 
individualism (Bryerton, 2016; DiAngelo, 2010) as a lens through which to reveal the unseen and unquestioned ways white privilege is maintained among students who continue to reap advantage while students of color continue to be marginalized. It is quite possible my study and analysis contain a blind spot stemming from me identifying as a white male and the accompanying, inherent difficulty of not being able sufficiently to interrogate my own whiteness. No matter the care or time put into this study and future studies, my worldview is likely always to be situated in that of a white, middle-class, cisgender male. Additionally, my re-analysis of descriptive statistics is not meant to appropriate, overwrite, or claim the epistemological arena of people of color. Any lack in my ability to self-reflect on my own identity position from which I make claims is mine alone. This limitation affects this study by way of the career pathways and course enrollments I chose to analyze. Some members of my audience, in particular people of color, may suggest I missed opportunities to expose far greater structural inequities than those exposed herein; it is also possible more strenuous claims of inequity are beyond the scope of this study and beyond findings either the ISBE data or descriptive statistics can yield.

\section{Data Collection}

ISBE staff work with member school districts and each school's personnel are charged with entering and remitting CTE enrollment data to ISBE. Anomalies, if suspected by ISBE, are corrected and verified with the sending school. Incorrect data entries can limit the accuracy of numerical claims. This limitation exists chiefly because humans are fallible and data entry, despite robust student information systems, is prone to human error. I believe the effect of anomalies on the dataset I utilize to be minimal. Although I do not utilize longitudinal data, I viewed prior years of enrollment data to provide some sense of a baseline and to ensure enrollment figures were not drastically different than previous years. The descriptive statistics I 
present on course enrollments are intended to exhibit phenomenon of importance for CTE teachers, administrators, and academic advisers, not necessarily fealty to a normal distribution.

Using data in the aggregate allowed me to cast a wide net to understand who enrolls in CTE courses, but my understanding comes with limitations. Highlighting disparity at the aggregate level can mask an individual school's course enrollments thus hiding potentially equitable and notable CTE enrollments. For instance, when providing information about STEM enrollments, a school with a racially diverse STEM-related course enrollments will be lost by my use of the aggregate. Lessening or eliminating this limitation requires looking at individual course enrollments for each school, an arduous task outside the scope of this study.

Additionally, the data reflects multiple headcounts. Therefore, a student who enrolls in three CTE courses adds to the CTE student total three times. Without duplicate headcounts, a more accurate total of the number of CTE students in the state emerges.

\section{Recommendations for Practice}

Policymakers and practitioners interested in social justice and equity in education and who are concerned with a lack of students of color in CTE should consider narrowing future research by focusing on healthcare-related CTE courses. Healthcare-related courses display remarkably even enrollments across gender, ethnic, and special-population lines. Future researchers might collect best practices from CTE practitioners to share with peers and schools determined to increase enrollments among students of color and students in special populations. Research with a focus on why healthcare courses report racial parity could involve fieldwork in which rich, descriptive data includes students' voices—especially students of color-as well as voices of faculty, families, and administrators. Such rich, descriptive data holds the possibility to provide detailed information on the motivations and reasons for how students select particular 
healthcare courses and any systemic barriers they feel they face in CTE. These keen insights would assist and guide policymakers in crafting legislation capable of ushering more students of color into CTE.

\section{Credentials}

I argue there should be less focus on industry-recognized credentials and more focus on helping students traverse the obstacles that are sure to appear along students' career pathways. Although seamless pathways exist on paper, the reality of a student being able linearly to navigate with ease a high school CTE course and then go on to post-secondary training and education to find work in a chosen occupation is anything but easy. Were it easy, then matriculation and retention of students in career pathways would be more robust than in Illinois schools. Furthermore, if all seamless transition efforts worked, one would expect few students, especially students of color, to enter into community colleges' or universities' developmental education courses. The structure, not students, needs to be questioned to understand why more students of color do not enroll in CTE courses.

If policymakers want to identify indicators useful for enrolling more students of color into CTE courses, they can entice CTE instructors to conduct their own field work to provide university researchers more data points on which to base policies. Based on the analysis I offer, identifying CTE indicators will be most useful when drawn using both quantitative and qualitative methods. A reliance solely on quantitative data, as argued earlier in this study, risks decision-making that fails to take into account the racial complexity of students and their lived experiences. Likewise, focusing only on qualitative data risks yielding data too narrow with which to craft meaningful policy. Mixed-methods research would help provide both thick descriptive and broad data so vital to understanding student motivations about CTE. Coupled 
with a variety of relevant and supporting data points, such a methodology offers researchers the ability to create models where unique patterns and phenomenon can be used to foster a better understanding of the importance of CTE in Illinois' public high schools.

\section{Reward CTE Systems That Promote Sampling}

Perkins IV legislation, now Perkins V, and its mandates are used are used to determine CTE program funding at the secondary and post-secondary levels. Systems receive more monies when students become concentrators, or students who go on to take more than one course in a particular CIP code (ISBE, n.d.b). Without much introspection this can seem beneficial. The system is set up to reward students who show a propensity to want to learn a subject more deeply. When students continue down a career path, gaining more skills, the likelihood of employment in a particular path increases. I argue specializing too early in one's career diminishes curiosity and growth opportunities (Epstein, 2019). Media outlets routinely report that the jobs students will hold in future have yet to exist. Were this true, students who take courses within narrow career pathways may inadvertently reduce their career options. Instead, legislators should consider rewarding CTE systems that value students' sampling and trying a variety of courses. In this manner, students can begin to recognize patterns across disciplines and draw from a variety of experiences to solve future problems.

\section{Recruit Instructors of Color}

One of CTE's problems in need of solving is that the field lacks instructors of color. Policies to recruit and retain secondary CTE instructors of color would likely assist the field in attracting a more racially diverse student body; but this recommendation's implementation must go beyond mere tokenism. Offering student loan forgiveness or special tax credits could be considered ways of recruiting people of color into STEM-focused career pathways, for example. 
Suffice it to say, this recommendation is fraught with difficulty, but state governments could begin by eliminating alternative paths to CTE secondary teacher certification. The authors of the U.S. Department of Education's (2014) National Assessment of Career and Technical Education report, "while some states require all CTE instructors to meet the same licensure and certification requirements as their academic counterparts, most allow CTE instructors to enter the teaching profession by substituting work experience for academic coursework" (p. 24). This is problematic because it negates the importance of all other curricula in teacher education programs and prioritizes technical skills.

While I cannot deny a veteran journeyman electrician may have more-relevant work experience than a recent CTE college graduate, it is likely the graduate has experienced both pedagogy and exposure to racially diverse viewpoints. Instructors who take an alternative path to certification may come from industries and companies largely devoid of underrepresented groups, in particular women and people of color. No doubt there may be individuals who seek alternative paths to teacher certification who are master technicians, but caution must be exercised by CTE-offering institutions that they are not put into positions of power to run roughshod over students. Proponents of alternative certification will point to the difficulty of finding instructors with particular and unique skill sets. This argument, while logical, is not supported by the data. Over half of all Illinois' CTE courses are introductory and therefore teachers trained as generalists possess sufficient knowledge. Highly qualified content experts, while perhaps preferred, are not needed for the largest number of CTE courses currently taught. For CTE courses to reflect the population's racial diversity across career pathways, hiring CTE instructors of colors is integral to make Illinois CTE programs and students' job outcomes far more equitable for all of Illinois' students. 


\section{REFERENCES}

Advance CTE. (2017) Career clusters. Retrieved from https://careertech.org/career-clusters American Association of Community Colleges. (1984). Putting America back to work: The Kellogg leadership initiative. A report and guidebook. Retrieved from http://files.eric.ed.gov/fulltext/ED245738.pdf

Andersen, K. (2017). Fantasyland: How America went haywire: A 500-year history. New York, NY: Random House.

Andrade, M. S. (2016). Curricular elements for learner success-2 $21^{\text {st }}$ century skills. Journal of Education and Training Studies, 4(8), 143-149.

Annamma, S. A. (2015). Whiteness as property: Innocence and ability in teacher education. Urban Review: Issues and Ideas in Public Education, 47(2), 293-316.

Apple, M. W. (2004). Ideology and curriculum. New York, NY: Routledge.

Applebaum, B. (2003). White privilege, complicity and the social construction of race. Educational Foundations, 17(4), 5-20.

Asunda, P. A., Kim, E. S., \& Westberry, R. (2015). Technology student characteristics: Course taking patterns as a pathway to STEM disciplines. Journal of Technology Education, $27(1), 2-22$.

Badger, E. (2017, August 24). How redlining's racist effects lasted for decades. The New York Times. Retrieved from https://www.nytimes.com/2017/08/24/upshot/how-redliningsracist-effects-lasted-for-decades.html

Barnett, E. A., \& Bragg, D. D. (2006). Academic pathways and increased opportunities for underserved students: Crosscutting themes and lessons learned. New Directions for Community Colleges, 135, 101-107. 
Bankston, C. (2011). The mass production of credentials: Subsidies and the rise of the higher education industry. Independent Review, 15(3), 325-349.

Bell, D. (1989). After we're gone: Prudent speculations on America in a post-racial epoch. Saint Louis University Law Journal, 34, 393-405.

Bonilla-Silva, E. (2005). Racism without racists: Color-blind racism and the persistence of racial inequality in the United States. Educational Studies, 38(2), 177-179.

Bourdieu, P., \& Passeron, J. C. (1990). Reproduction in education, society and culture. Beverly Hills, CA: Sage.

Bowles, S., \& Gintis, H. (1976). Schooling in capitalist America: Educational reform and the contradictions of economic life. New York, NY: Basic Books.

Boykin, A. W. (2011). Creating the opportunity to learn: Moving from research to practice to close the achievement gap. Alexandria, VA: ASCD.

Bragg, D. D. (2005). Building real partnerships. In D. Hull (Ed.), Career pathways: Education with a purpose (pp. 169-192). Waco, TX: Cord Communications.

Bragg, D. D. (2007). Teacher pipelines: Career pathways extending from high school to community college to university. Community College Review, 35(1), 10-29.

Bryerton, W. (2016). That "every man for himself" thing: The rationales of individualism among the urban poor. Sociological Inquiry, 86(1), 79-102.

Carnevale, A. P., Jayasundera, T., \& Hanson, A. R. (2012, September). Career and technical education. Five ways that pay. Washington, DC: Georgetown Public Policy Institute, Center on Education and the Workforce, Georgetown University. Retrieved from https://cew.georgetown.edu/wp-content/uploads/2014/11/CTE.FiveWays.FullReport.pdf 
Carter, P. L. (2012). Stubborn roots: Race, culture, and inequality in U.S. and South African schools. New York, NY: Oxford University Press.

Chapman, T. K. (2013) You can't erase race! Using CRT to explain the presence of race and racism in majority white suburban schools. Discourse: Studies in the Cultural Politics of Education 34(4), 611-627.

Chicago Public Schools. (2015). School data: Demographics: Racial/ethnic report. Chicago, IL: CPS. Retrieved from http://cps.edu/SchoolData/Pages/SchoolData.aspx

Coates, T.-N. (2015). Between the world and me. New York, NY: Random House.

Collins, R. (1979). The credential society: An historical sociology of education and stratification. New York, NY: Academic Press.

Crotty, M. (1998). The foundations of social research: Meaning and perspective in the research process. Thousand Oaks, CA: Sage.

Dadgar, M., \& Weiss, M. J. (2012). Labor market returns to sub-baccalaureate credentials: How much does a community college degree or certificate pay? New York, NY: Community College Research Center, Columbia University.

Delgado, R., \& Stefancic, J. (2012). Critical race theory: An introduction. New York, NY: New York University Press.

DeFeo, D. J. (2015). Why are you here? CTE students' enrollment motivations and career aspirations. Career and Technical Education Research, 40(2), 82-98.

Deloitte and The Manufacturing Institute. (2015). The skills gap in U.S. manufacturing, 2015 and beyond. Washington, DC: The Manufacturing Institute. Retrieved from http://www.themanufacturinginstitute.org/ /media/827DBC76533942679A15EF7067A7 04CD.ashx 
DiAngelo, R. J. (2010). Why can't we all just be individuals?: Countering the discourse of individualism in anti-racist education. Interactions: UCLA Journal of Education \& Information Studies, 6(1), 1-24.

DuBois, W. E. B. (1903). The talented tenth. In B. T. Washington (Ed.), The Negro problem (pp. 30-75). New York, NY: James Pott \& Co. Retrieved from https://books.google.com/books?id=A8RtAAAAMAAJ\&printsec=titlepage \&source=gbs _summary_r\&cad $=0 \# \mathrm{v}=$ onepage $\& \mathrm{q} \& \mathrm{f}=$ false

Frankenberg, R. (1993). White women, race matters: The social construction of whiteness. Minneapolis, MN: University of Minnesota Press.

Gillborn, D. (2005). Education policy as an act of white supremacy: Whiteness, critical race theory and education reform. Journal of Education Policy, 20(4), 485-505.

Giroux, H. A. (1999). Vocationalizing higher education: Schooling and the politics of corporate culture. College Literature, 26(3), 147-161.

Giroux, H. A. (2014). Neoliberalism's war on higher education. Chicago, IL: Haymarket Books.

Giroux, H. A. (2019). The terror of the unforeseen. Los Angeles, CA: Los Angeles Review of Books.

Gordon, H. (2008). The history and growth of career and technical education in America. Long Grove, IL: Waveland.

Grubb, W. N. (1995). Postsecondary education and the sub-baccalaureate labor market: Corrections and extensions. Economics of Education Review, 14(3), 285-299.

Grubb, W. N., \& Lazerson, M. (2004). The education gospel: The economic power of schooling. Cambridge, MA: Harvard University Press. 
Guerrero, I. (2016, December 9). Race in the Rock River Valley: Minority nurses in demand in Rockford, across U.S. Rockford Register Star. Retrieved from http://www.rrstar.com/news/20161209/race-in-rock-river-valley-minority-nurses-indemand-in-rockford-across-us

Hamilton, A. F., Malin, J., \& Hackmann, D. (2015). Racial/ethnic and gender equity patterns in Illinois high school career and technical education coursework. Journal of Career \& Technical Education, 30(1), 29-52.

Harris, C. I. (1993). Whiteness as property. Harvard Law Review, 106(8), 1707-1791.

Hayward, G. C., \& Benson, C. S. (1993). Vocational-technical education: Major reforms and debates 1917-present. Washington, DC: U.S. DOE Office of Vocational and Adult Education. Retrieved from http://files.eric.ed.gov/fulltext/ED369959.pdf

Hull, D. M. (2005). Career pathways: Education with a purpose. Waco, TX: CORD Communications.

Illinois Department of Agriculture. (2019). Facts about Illinois agriculture. Retrieved from https://www2.illinois.gov/sites/agr/About/Pages/Facts-About-Illinois-Agriculture.aspx

Illinois State Board of Education. (n.d.a) Illinois report card. Retrieved from http://www.illinoisreportcard.com/district.aspx?source=profile\&Districtid=04101205025.

Illinois State Board of Education. (n.d.b) Retrieved from https://www.isbe.net/Pages/SearchResults.asp $\mathrm{k} \mathrm{k}=\mathrm{cte}$.

Illinois State Board of Education. (2012). Education for employment (EFE) training for the Illinois state course system and the student information system. Retrieved from https://www.isbe.net/Documents/efe-iscs-sis20121203.pdf\#search=efe 
Illinois State Board of Education. (2016a). Fall enrollments. Retrieved from https://www.isbe.net/Pages/Fall-Enrollment-Counts.aspx

Illinois State Board of Education. (2016b). CTE fact sheet. Retrieved from https://www.isbe.net/Documents/CTE_fact_sheet.pdf\#search=cte $\% 20$ fact $\% 20$ sheet

Illinois State Board of Education. (2016c). State graduation requirements. Retrieved from https://www.isbe.net/Documents/grad_require.pdf

Illinois State Board of Education. (2017a). Change history. Retrieved from https://www.isbe.net/Documents/data_elements_alltabs.pdf

Illinois State Board of Education. (2017b). ISBE student information system. Retrieved from https://www.isbe.net/Documents/file_format_layout.pdf

Illinois State Board of Education. (2019). Agricultural education. Retrieved from https://www.isbe.net/Pages/Agriculture-Education.aspx

Kerckhoff, A. C., \& Bell, L. (1998). Hidden capital: Vocational credentials and attainment in the United States. Sociology of Education, 71(2), 152-174.

Kowalski, T., \& Lasley, II, T. J. (Eds.). (2009). Handbook of data-based decision making in education. New York, NY: Routledge.

Ladson-Billings, G., \& Tate, W. (1995). Toward a critical race theory of education. Teachers College Record, 97(1), 47-68.

Lee, S. J. (2005). Up against whiteness: Race, school and immigrant youth. New York, NY: Teachers College Press.

Leonardo, Z. (2002). The Souls of White Folk: Critical pedagogy, whiteness studies, and globalization discourse. Race, Ethnicity \& Education, 5(1), 29-50. 
Leonardo, Z. (2007). The war on schools: NCLB, nation creation and the educational construction of whiteness. Race, Ethnicity \& Education, 10(3), 261-278.

Lewis, T., \& Cheng, S. (2006). Tracking, expectations, and the transformation of vocational education. American Journal of Education, 113(1), 67-99.

Loeb, S., Dynarski, S., McFarland, D., Morris, P., Reardon, S., \& Reber, S. (2017). Descriptive analysis in education: A guide for researchers (NCEE 2017-4023). Washington, DC: National Center for Education Evaluation and Regional Assistance.

Mantzoukas, S. (2007). The evidence-based practice ideologies. Nursing Philosophy, 8(4), 244255.

Markovits, D. (2019). The meritocracy trap: How America's foundational myth feeds inequality, dismantles the middle class, and devours the elite. New York, NY: Penguin.

Matias, C. E., Henry, A. \& Darland, C. (2017). The twin tales of whiteness: Exploring the emotional roller coaster of teaching and learning about whiteness. Taboo: The Journal of Culture \& Education, 16(1), 7-29.

McLaren, P. (2000). Whiteness is.... The struggle for postcolonial hybridity. In J. Kinchella \& S. Steinberg (Eds.), White reign: Deploying whiteness in America (pp. 63-65). New York, NY: St. Martin's Press.

Mijs, J. J. B. (2016). The unfulfillable promise of meritocracy: Three lessons and their implications for justice in education. Social Justice Research, 29(1), 14-34.

Modica, M. (2015). "My skin color stops me from leading”: Tracking, identity, and student dynamics in a racially mixed school. International Journal of Multicultural Education, 17(3), 76-90. 
Morrell, C., \& Parker, C. (2015). Solving the education equation: A new model for improving STEM workforce outcomes through academic equity. Gap, PA: National Alliance for Partnerships in Equity. Retrieved from http://www.napequity.org/solving-educationequation

National Association of Manufacturers. (2015). Competing to win: A detailed roadmap for the President and Congress [White paper]. Washington, DC: National Association of Manufacturers. Retrieved from https://www.nam.org/competing-to-win/

National Association of State Administrators of Family and Consumer Science. (n.d.). National standards and competencies: National standards 3.0. Retrieved from http://www.nasafacs.org/national-standards-and-competencies.html

National Commission on Excellence in Education. (1983). A nation at risk: The imperative for educational reform. Washington, DC: The National Commission on Excellence in Education. Retrieved from https://www.edreform.com/wpcontent/uploads/2013/02/A_Nation_At_Risk_1983.pdf

Oakes, J. (2005). Keeping track: How schools structure inequality. New Haven, CT: Yale University Press.

Obama, B. (2009, Tuesday, February 24). Remarks of President Barack Obama, as prepared for delivery-Address to joint session of Congress. https://obamawhitehouse.archives.gov/the-press-office/remarks-president-barack-obamaaddress-joint-session-congress

Oyserman, D. (2006). High power, low power, and equality: Culture beyond individualism and collectivism. Journal of Consumer Psychology 16(4), 352-256. 
Patton, M. Q. (2002). Qualitative research \& evaluation methods (3 ${ }^{\text {rd }}$ ed.). Thousand Oaks, CA: Sage.

Perez, S. A., \& Copenhaver, C. C. (1998) Certificates on center stage: Occupational education for a working economy. Leadership Abstracts, 11(1-10), 1-4.

Project Lead the Way. (n.d.). Inspiring, engaging, and empowering preK-12 students. Indianapolis, IN: Project Lead the Way. Retrieved from https://www.pltw.org/

Reason, R. D., \& Evans, N. J. (2007). The complicated realities of whiteness: From color blind to racially cognizant. New Directions for Student Services, 2007(120), 67-75.

Rockford Register Star Editorial Board. (2017, October 7). Our view: More women, minorities needed for first responders [Op-ed]. Retrieved from https://www.rrstar.com/opinion/20171007/our-view-more-women-minorities-needed-forfirst-responders

Rock Valley College. (n.d.) Health sciences center: About. Retrieved from https://www.rockvalleycollege.edu/About/health-sciences-center.cfm

Rojewski, J. W., \& Xing, X. (2013). Treatment of race/ethnicity in career-technical education research. Career and Technical Education Research, 38(3), 245-256.

Semali, L. (2000). Perspectives of the curriculum of whiteness. In J. Kincheloe, \& S. Steinberg (Eds.), White reign: Deploying whiteness in America (pp. 177-192). New York, NY: St. Martin's Press.

Seron, C., Silbey, S., Cech, E., \& Rubineau, B. (2018). “I am not a feminist, but...”: Hegemony of a meritocratic ideology and the limits of critique among women in engineering. Work \& Occupations, 45(2), 131-167. 
Solorzano, D., \& Yosso, T. (2001). From racial stereotyping and deficit discourse: Toward a critical race theory in teacher education. Multicultural Education, 9(1), 2-8.

Soulé, H., \& Warrick, T. (2015). Defining $21^{\text {st }}$ century readiness for all students: What we know and how to get there. Psychology of Aesthetics, Creativity, and the Arts, 9(2), 178-186.

Tranby, E., \& Hartmann, D. (2008). Critical whiteness theories and the evangelical "race problem": Extending Emerson and Smith's Divided by Faith. Journal for the Scientific Study of Religion, 47(3), 341-359.

Thompson, A. (1998). Not the color purple: Black feminist lessons for educational caring. Harvard Educational Review, 68(4), 522-555.

Torpey, E. (2015). Clusters, pathways, and BLS: Connecting career information. Washington, DC: U.S. Department of Labor Bureau of Labor Statistics. Retrieved from https://www.bls.gov/careeroutlook/2015/article/career-clusters.htm

Urban, W. J., \& Wagoner, J. L. (2014). American education: A history. New York, NY: Routledge.

U.S. Census Bureau. (2015). New census bureau report analyzes U.S. population projections. Retrieved from https://www.census.gov/newsroom/press-releases/2015/cb15-tps16.html

U.S. Census Bureau. (2018a). Older people projected to outnumber children for first time in U.S. history. Retrieved from https://www.census.gov/newsroom/press-releases/2018/cb18-41population-projections.html

U.S. Census Bureau. (2018b). QuickFacts: Rockford city, Illinois. Retrieved from https://www.census.gov/quickfacts/rockfordcityillinois 
U.S. Congress. (1862). Morrill Act. Retrieved from

http://www.ourdocuments.gov/print_friendly.php?page=transcript\&doc $=33 \&$ title $=$ Transc ript + of + Morrill + Act $+\% 281862 \% 29$

U.S. Congress. (1917). Smith-Hughes Act. Retrieved from https://www.scribd.com/document/49149021/The-Vocational-Education-Act-of-1917-orthe-Smith-Hughes-Act-1917

U.S. Congress. (1963). Vocational Act of 1963. Retrieved from https://archive.org/stream/ERIC_ED019402\#page/n6/mode/1up

U.S. Congress. (1976). Education Amendments of 1976. Retrieved from https://www.gpo.gov/fdsys/pkg/STATUTE-90/pdf/STATUTE-90-Pg2081.pdf

U.S. Congress. (1984). Carl D. Perkins Vocational Education Act. Retrieved from https://www.govtrack.us/congress/bills/98/hr4164/text

U.S. Congress. (2006). Carl D. Perkins Vocational and Technical Education Act. Retrieved from https://s3.amazonaws.com/PCRN/uploads/perkins_iv.pdf

U.S. Department of Education. (2001). No Child Left Behind: The Elementary and Secondary Education Act. Retrieved from http://www2.ed.gov/nclb/landing.jhtml?src=rn

U.S. Department of Education. (2006). Programs of study. Retrieved from https://cte.ed.gov/initiatives/programs-of-study

U.S. Department of Education. (2014, October 30). Obama administration announces final rules to protect students from poor-performing career college programs. Retrieved from https://www.ed.gov/news/press-releases/obama-administration-announces-final-rulesprotect-students-poor-performing-career-college-programs 
U.S. Department of Education National Center for Education Statistics. (2002). Classification of instructional programs. Retrieved from http://nces.ed.gov/pubs2002/cip2000/

U.S. Department of Education National Center for Education Statistics. (2016). Exploring the foundations of the future STEM workforce: $K-12$ indicators of postsecondary STEM success. Retrieved from https://ies.ed.gov/ncee/edlabs/regions/southwest/pdf/REL_2016122.pdf

U.S. Department of Education National Center for Education Statistics. (2019). Concentration of public school students eligible for free or reduced-price lunch. Retrieved from https://nces.ed.gov/programs/coe/indicator_clb.asp

U.S. Department of Education Office of Career, Technical, and Adult Education, Division of Academic and Technical Education (n.d.). Indicators of performance. Retrieved from https://cte.ed.gov/accountability/core-indicators

U.S. Department of Health and Human Services. (2017). FY 2017 annual performance report. Retrieved from https://www.hrsa.gov/about/budget/fy17annualperformancereport.pdf

U.S. Department of Labor, Employment and Training Administration. (n.d.). Trade adjustment assistance: Community college and career training. Retrieved from https://doleta.gov/taaccct/

U.S. Department of Labor. (2007). Nontraditional occupations. Retrieved from https://www.dol.gov/wb/factsheets/nontra2007.htm

U.S. Department of Labor. (2016). Labor force statistics from the current population survey. Retrieved from https://www.bls.gov/cps/cpsaat11.htm Valencia, R. (2010). Dismantling contemporary deficit thinking: Educational thought and practice. New York, NY: Routledge. 
Vogt, P. (2007). Quantitative research methods for professionals. Boston, MA: Pearson.

Wang, K., T., Castro, A. J., \& Cunningham, Y. L. (2014) Are perfectionism, individualism, and racial color-blindness associated with less cultural sensitivity? Exploring diversity awareness in white prospective teachers. Journal of Diversity in Higher Education, 7(3), $211-225$.

Washington, B. T. (1903). Industrial education for the Negro. Retrieved from http://www.online-literature.com/booker-washington/3920/ 


\section{APPENDIX A: VARIABLE DESCRIPTIONS}

1. Location: The location refers to the Illinois educational intermediary organization called Education for Employment Regional Delivery Systems (EFE). Illinois has 58 EFEs each having a system director. Enrollment data for an EFE location is based on the public high schools that reside in each EFE's unique geographical area. For example, EFE 10 is Chicago Public Schools.

2. Course Name: The approved state course title schools attach to their respective courses. Each course name is linked to a corresponding CIP code linked to Perkins.

3. FRL: Illinois students who qualify for free and reduced lunch (FRL) are coded in the data set as $0=$ not on free and reduced lunch, $1=$ student on free and reduced lunch. FRL is a proxy for socio economic status (SES) since financial eligibility requirements are used to determine FRL status.

4. STEM: STEM is not a variable made by ISBE officials. The researcher coded Illinois high school CTE courses as not STEM $=0$ and STEM $=1$. In order to make the determination as to what was a STEM course and what was not, BLS descriptions of STEM occupations were used. Illinois course names and CIP codes were compared to O*NET and DOL data descriptions and coded accordingly. Course titles aligning with DOL information indicating STEM career pathways was coded with a 1 and the courses not aligning with a STEM pathway were coded as 0 .

5. Gender: Females are coded as 0 and males as 1 .

6. Race: ISBE uses seven categories of race. In the raw data set, American Indian and Pacific Islander and More Than One Race represented a small number of students so they 
were recoded into "Other." Race variables for this study are as follows: $1=$ White, $2=$ Black, 3 = Hispanic, $4=$ Asian, $5=$ Other.

7. RCDTS: Region County District Type Schools is a 15-digit unique identifier for each educational institution.

8. Grade: Refers to students' year in school with values of $9,10,11$ and 12 .

9. NT: Nontraditional. The Department of Labor defines nontraditional occupations as one in which one gender comprises 25 percent or less of total employment. For instance, an electrician is considered a nontraditional occupation from women because only $1.7 \%$ of those employed as electricians are female (U.S. DOL, 2007).

10. DH: The term "Displaced Homemaker" means an individual who... "has worked primarily without remuneration to care for a home and family, and for that reason has diminished marketable skills (ISBE, 2017b). Few Illinois high school students fall into this category.

11. LEP: Students who have a native language other than English.

12. IEP: Students who receive services under the Individuals with Disabilities Education Act (IDEA).

13. Single Parent: "Single Parent" means an individual who (A) is unmarried or legally separated from a spouse; and (B) (i) has a minor child or children for which the parent has either custody or joint custody; or (ii) is pregnant. (ISBE, 2017b p. 147).

14. CIP: "The Classification of Instructional Programs (CIP) provides a taxonomic scheme that supports the accurate tracking and reporting of fields of study and program completions activity” (U.S. DOE NCES, 2002 ๆ. 1). 
The U.S. Department of Education's Office of Career, Technical, and Adult Education (OCTAE) (n.d.), with respect to Perkins funding, has the following Core Indicators of Performance for the secondary level:

1S1: Academic Attainment in Reading/Language Arts

1S2: Academic Attainment in Mathematics

2S1: Technical Skill Attainment: Percentage derived by taking the number of CTE concentrators who took and passed an industry recognized assessment in the reporting year divided by the total amount of students who took industry recognized assessments.

\section{S1: Secondary School Completion}

4S1: Student Graduation Rate

5S1: Secondary Placement

6S1: Nontraditional Participation:

[Percentage derived by] CTE participants from underrepresented gender groups who participated in a program that leads to employment in nontraditional fields during the reporting year [divided by the] number of CTE participants who participated in a program that leads to employment in nontraditional fields during the reporting year. 6S2: Nontraditional Completion

[Percentage derived by] CTE concentrators from underrepresented gender groups who participated in a program that leads to employment in nontraditional fields during the reporting year [divided by the] number of CTE concentrators who participated in a program that leads to employment in nontraditional fields during the reporting year. 


\section{APPENDIX B: PLAN OF STUDY}

SAMPLE Career Pathway Plan of Study

Career Cluster: Hospitality \& Tourism Career Pathway: Restaurant \& Food/Beverage Services CIP Title: Cooking and Related Culinary Arts CIP: 1205000000

This Career Pathway Plan of Study Tool can serve as a guide, along with other career planning materials, as you continue developing your Program of Study. Courses listed within this plan are only recommended coursework and should be individualized to meet each learner's educational and career goals. All plans should meet high school graduation requirements as well as college entrance requirements.

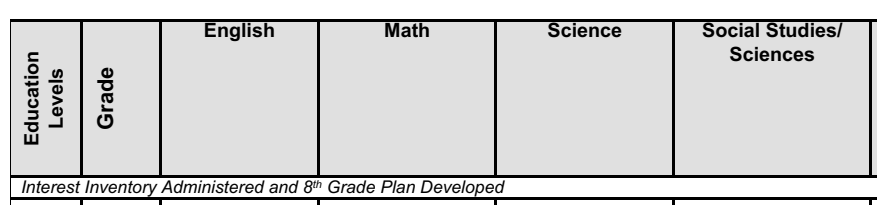

\begin{tabular}{|c|c|}
\hline $\begin{array}{c}\text { Other Required } \\
\text { Courses, } \\
\text { Recommended } \\
\text { Electives, and } \\
\text { Learner Activities }\end{array}$ & $\begin{array}{c}\text { Career \& Technical Courses and/or } \\
\text { Degree Major Courses }\end{array}$ \\
& \\
\hline
\end{tabular}

\section{Occupation Relating to this Pathway}

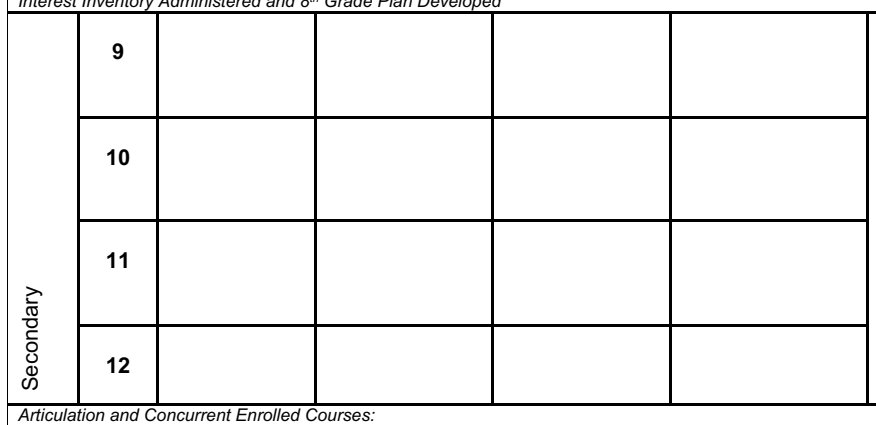
need to meet local graduation

requirements as well as college entrance requirements.

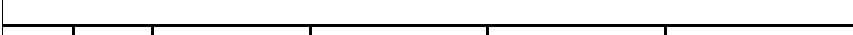

All plans of study

All plans of study
need to meet need to meet
learners' career goals with regard to required degrees,
licenses, and/or

licenses, and/or,
certifications.

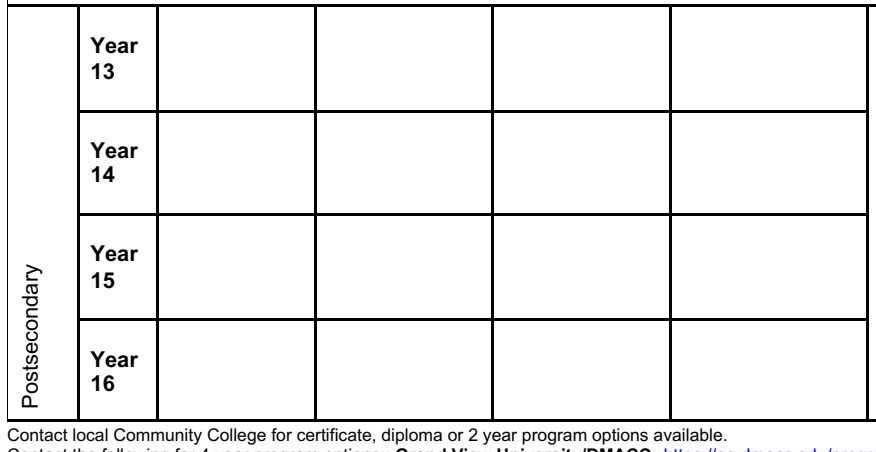

